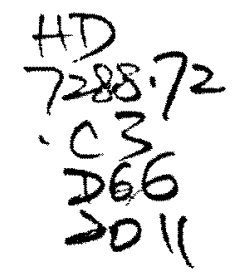

SPATIAL MISMATCH IN THE TORONTO CENSUS METROPOLITAN AREA: EXAMINING THE COMMUTING PATTERNS OF IMMIGRANTS

by

Liam Donaldson, Honours BA, University of Western Ontario, 2008

A Major Research Paper

presented to Ryerson University

in partial fulfillment of the requirements for the degree of

Master of Planning

in

Urban Development

Toronto, Ontario, Canada, 2011

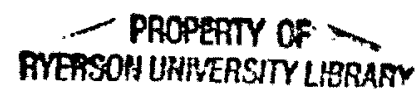

(C) Liam Donaldson 2011 
Author's Declaration

I hereby declare that I am the sole author of this major research paper.

I authorize Ryerson University to lend this paper to other institutions or individuals for the purpose of scholarly research.

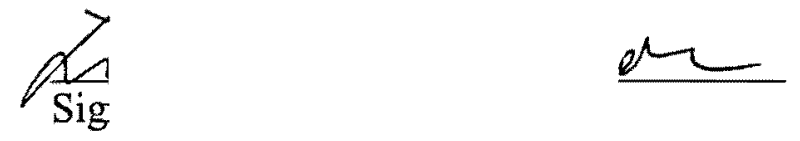

I further authorize Ryerson University to reproduce this paper by photocopying or by other means, in total or in part, at the request of other institutions or individuals for the purpose of scholarly research. 


\title{
SPATIAL MISMATCH IN THE TORONTO CENSUS METROPOLITAN AREA: EXAMINING THE COMMUTING PATTERNS OF IMMIGRANTS
}

C Liam Donaldson, 2011

\author{
Master of Planning \\ in \\ Urban Development \\ Ryerson University
}

\begin{abstract}
The spatial mismatch hypothesis argues that the geographic separation between jobs and housing has an adverse effect on the employment outcomes of ethnic minorities. This research paper tests this assumption for immigrant populations in the Toronto Census Metropolitan Area through mapping, cross tabulation and a generalized ordered logit model to determine whether immigrants are at a disadvantage in both the labour market and in terms of commuting distance when compared with Canadian born residents. The results of this study suggest that immigrants are more likely to live over 5 kilometres away from work and that they experience more difficulty in negotiating longer commutes due to higher unemployment rates, lower median household incomes and a greater reliance on transit. In contrast, Canadians are more likely to make daily commutes of over 15 kilometres, however, they are often more capable than immigrants of travelling these increased distances.
\end{abstract}

key words: spatial mismatch; immigrants; Toronto; commute distance 


\section{Acknowledgements}

This research paper could not have been written without the help of my supervisor Dr. Murtaza Haider who encouraged and challenged me throughout this learning process. I would also like to thank Dr. Sandeep Agrawal for his timely and constructive comments during the latter stages of the project. 


\section{Table of Contents}

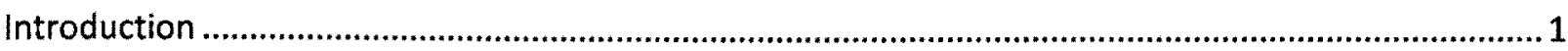

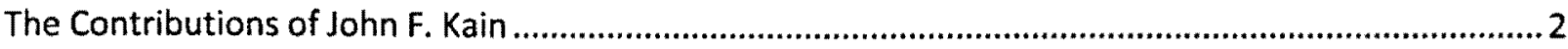

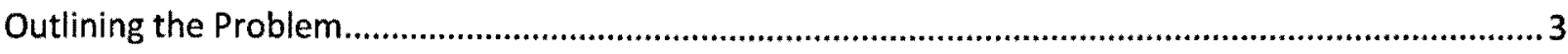

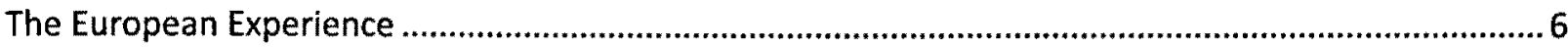

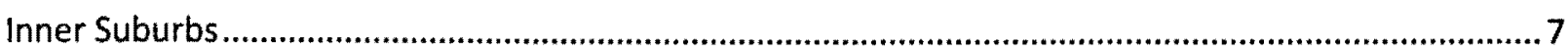

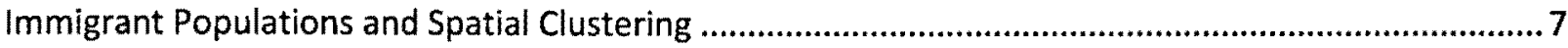

The Link Between Transportation and Employment Outcomes............................................................. 8

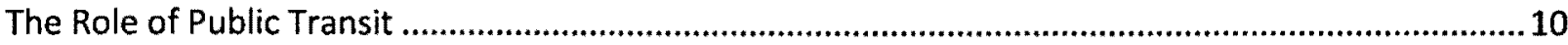

Spatial Structure and Demographics of the Toronto Census Metropolitan Area....................................11

Statistical Analysis - Cross Tabulation .................................................................................................13

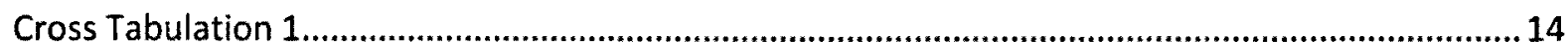

Cross Tabulation 2

Cross Tabulation 3

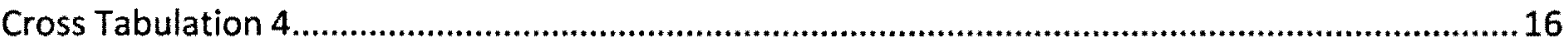

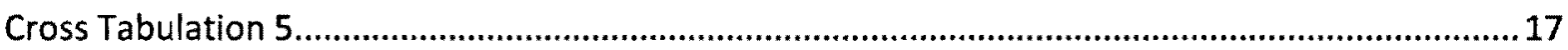

Cross Tabulation 6

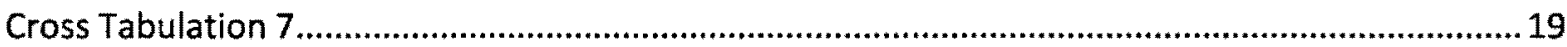

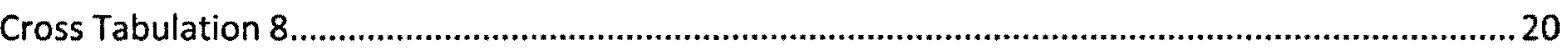

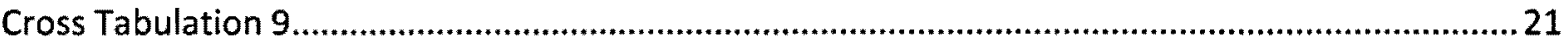

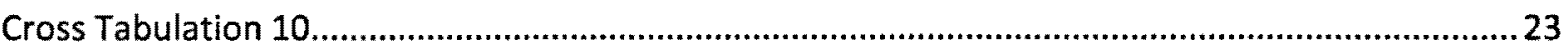

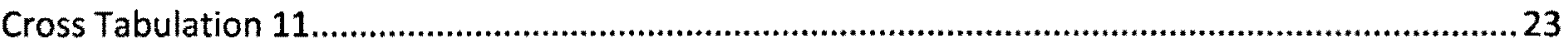

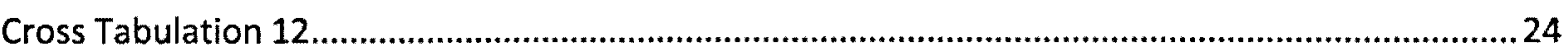

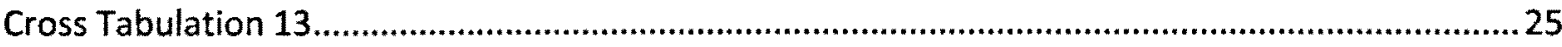

Cross Tabulation 14

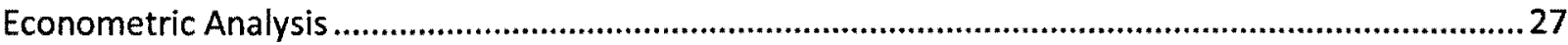

Results of the Generalized Ordered Logistic Regression ........................................................................33

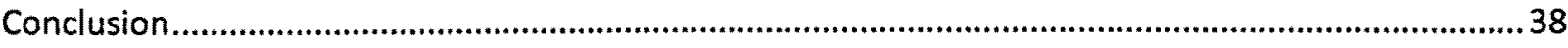

References 


\section{List of Maps and Tables}

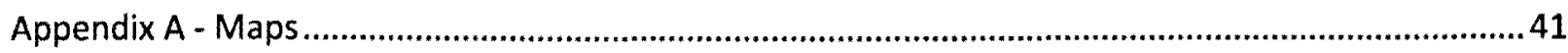

Map 1 - Municipal Boundary Map with Census Subdivisions .....................................................4 41

Map 2 - Percentage of Population who are Immigrants.......................................................442

Map 3 - Percentage of Population who are Recent Immigrants...................................................4 43

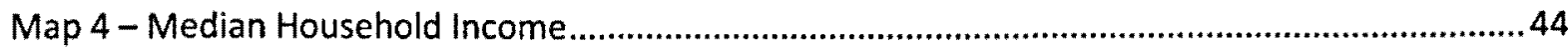

Map 5 - Employment Density (Jobs per Hectare) ..............................................................45

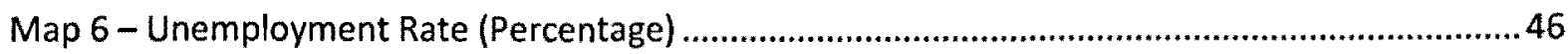

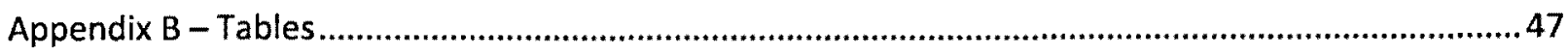

Table 1

Table 2 


\section{Introduction}

The spatial mismatch hypothesis (SMH) can be defined as the sociological, economic and political phenomenon associated with economic restructuring in which employment opportunities for low-income individuals are located far away from the areas in which they live (Arnott, 1998). The concept was first introduced by John F. Kain in his seminal study 'Housing Segregation, Negro Employment, and Metropolitan Decentralization' which considered the relationship between black inner city populations and access to lower-skilled employment in the suburbs (Kain, 1968). There have been numerous tests for the SMH among racial minorities since, yet only recently has research begun to test the implications of SMH among immigrants. At present, the results for immigrants are mixed, showing heterogeneity with respect to country of origin, length of residence, and status as a first or second generation immigrant (Painter, Liu \& Zhuang, 2007). Further, these studies have been conducted primarily in the United States and Europe with little attention being paid to the Canadian experience.

This study will begin with a literature review tracing the history and evolution of the spatial mismatch hypothesis from Kain to the present day. This review will summarize the numerous methodological approaches and measures used to test the spatial mismatch hypothesis along with key findings from studies of SMH amongst immigrant populations in American and European cities. The paper will conclude with an attempt to answer the question:

- Do immigrants in the Toronto Census Metropolitan Area travel further to work on average than non-immigrants?

To begin, the geography and spatial distribution of immigrants, household income groups, jobs and unemployment will be considered. This preliminary analysis is followed by a series of 
cross tabulations conducted using information gathered from the 2006 census and public use microdata files to uncover the relationships between a number of socioeconomic indicators. Finally, a generalized ordered logit model is estimated to control for socio-demographic factors in determining whether immigrants are significantly more likely to experience longer commuting distances than native born Canadians for work related trips.

\section{The Contributions of John F. Kain}

John Forest Kain was an empirical economist who significantly changed analysis and modelling in urban economics (Hanushek, 2008). His most notable contributions considered the interactions between race and urban location as well as the significance of housing segregation for African Americans. He also helped develop a number of general equilibrium urban simulation models capable of addressing important policy questions (Hanushek, 2008). His seminal paper on the spatial mismatch hypothesis, 'Housing Segregation, Negro Employment, and Metropolitan Decentralization' helped shape a line of inquiry that continues to this day (Kain, 1968). In this study, Kain proposes that housing segregation had kept African Americans in areas of the city where access to employment had decreased due to the decentralization of low-skilled employment to suburban regions. When coupled with the rising cost of commuting, employment for this segment of the population decreased.

Kain utilized data on employment location for Chicago (1956) and Detroit (1957) to divide both cities into ninety-eight workplace areas (Kain, 1968). With this data, Kain ran regression models using the Black percentage of total employment in the area as the dependent variable. The independent variables used in the study were the Black percentage of employed residents in the area - used as a proxy for employers' tendency to discriminate during the hiring 
process and the airline distance from the workplace area to either the nearest Black residence area (more than $2 \%$ Black) or to the nearest point in, what Kain terms, the Black ghetto (Kain, 1968). This last variable is considered a proxy for transportation costs and their effects on job information. Once these regressions were conducted a strong relationship between Black employment share and distance to work was uncovered. Over 75 percent of the total variance in the dependent variable could be explained by these regressions in Chicago and over $35 \%$ of this variance could be explained for Detroit (Kain, 1968). Kain would go on to investigate how racial segregation affected housing costs and home ownership rates for Blacks among other topics. His fascination with the intersection between geography, housing, labour markets and ethnicity was a significant contribution to the study of the economics of race, whose application to a wide variety of social issues is still being explored today.

\section{Outlining the Problem}

In the 40 years since Kain published his groundbreaking work, the spatial mismatch hypothesis has been tested using a variety of outcome measures ranging from commute distances, commute times, wages, job accessibility and employment ratios (Painter, Liu \& Zhuang, 2007). These methodological evolutions and refinements have reinforced our understanding of distance based isolation and the role it can play in the lives of poor, minority and immigrant communities while simultaneously clouding any attempts at developing a single, widely accepted definition of spatial mismatch. For the time being, however, it is safe to say that research has suggested that spatial access and barriers to employment is fundamental to the social and economic well being of a great many people. 
It is important to note that when we speak of space and its impact on racial employment differences that 'space' is essentially used as a surrogate for money, time, exchange of information and energy spent on commuting (Bauder, 2000). This distinction cannot be overstated and oftentimes researchers confuse this relationship or have become unaware of it altogether. The end result is subscribing to the fallacy that space and substance are somehow separate and that space exists independently of objects (Sayer, 1985). As Bauder (2000) has stated -

$$
\begin{aligned}
& \text { "The problem addressed by the SMH is not that } \\
& \text { space has independent causal properties but rather that resources, } \\
& \text { such as housing, occupations, commuting paths, } \\
& \text { and information networks are distributed unevenly among } \\
& \text { racial groups because of racial discrimination. The question } \\
& \text { that emerged in the } 1980 \text { s of whether the problem is "space" } \\
& \text { or "race" is irrelevant because residential } \\
& \text { segregation is a product of race." }
\end{aligned}
$$

Kain acknowledged and was conscious of these relationships from the outset. He never once privileged space over race - rather he sought to examine the effects of race through spatial processes. When one considers space as a barrier to employment, the ability to overcome these distances will not be equal for all workers. Put another way, longer commutes may not be problematic if they can be accomplished quickly while shorter commutes will remain challenging should there be no straightforward way to complete them. Oftentimes the ability to shorten a commute is contingent upon the availability and affordability of an automobile, family responsibilities and other time constraints. As a consequence, properly interpreting the results of an empirical study requires an intimate understanding of the spatial distribution of residences, economies and transportation networks within a given metropolitan region. In this sense, the 
spatial mismatch hypothesis cannot be universally accepted or denied for it applies to a subset of individuals in specific geographical areas at certain times (Preston and McLafferty, 1999).

The massive suburbanization of people and jobs that has occurred in the years following the Second World War is one of the most striking features of the Canadian urban landscape. In the $19^{\text {th }}$ and early $20^{\text {th }}$ centuries, Canadian cities were characterized by a small and dense central business district typically located near a major port or train station that acted as an interurban transport node (Gobillon, Selod \& Zenou, 2007). Residences were located near or within this central area due to the high intraurban cost of moving both people and goods (Mieszkowski and Mills, 1993). However, with the emergence of commuter trains, streetcars and the automobile residents became more able to travel greater distances in a shorter amount of time. This facilitated a move to the outlying areas of the city in order to consume more housing, while retaining employment in the city centre.

This outward trend of migration has resulted in a larger share of the urban population and employment opportunities being located in the outer suburbs, far from the more compact inner cities. The distances that separate housing from jobs have been increasing steadily in recent years, however, this increasing geographical separation is not simply an inner city problem. Not only has large scale suburbanization shifted jobs away from the city centre, it has also generated longer commutes both into the core and from suburb to suburb (Ong and Miller, 2005). Spatial mismatch, when defined simply as the physical separation between home and work, is therefore not confined to the inner city of modern metropolitan regions. Areas which experience high and low levels of spatial mismatch can be found throughout large urban agglomerations - in particular, many neighbourhoods can be devoid of jobs and therefore highly mismatched, yet workers may not experience difficulty in finding employment (Ong and Miller, 2005). 


\section{The European Experience}

Many European cities present a different pattern of urban and suburban form when compared to their North American counterparts. Several American cities have experienced 'white flight' which has coincided with a higher percentage of minorities in the urban population along with higher poverty and crime rates (Blázquez, Llano \& Moral, 2010). In many European metropolitan regions, poorer neighbourhoods are mainly located in the suburbs, while the urban core is the site of many of the wealthy neighbourhoods that attract residents of the upper social classes (Blázquez, Llano \& Moral, 2010). In addition, the more prosperous city centres have maintained their position as centres of employment yet many of the lower-skilled jobs have been displaced.

The urban structure of European cities, when compared with American metropolitan areas, is often viewed as more forgiving with regard to employment access for the disadvantaged. This contention is made due to the more compact layout, higher employment and population densities, lower levels of segregation and lower concentrations of poverty found in European cities (Korsu \& Wenglenski, 2010). While there is some truth to this statement, these positive attributes of European cities are often idealized when one compares them with American cities. The mass exodus of people and jobs to the margins of metropolitan areas, the lack of viable public transit options for suburban origin and destination trips and the prevalence of low income neighbourhoods are symptoms not only of American cities but of European cities as well. Many scholars, as well as those in the general public, assume that this urban crisis is primarily a North American issue, however, research into the spatial mismatch hypothesis shows that European cities are also at risk. 


\section{Inner Suburbs}

In truth, the dichotomy between the central city and the suburbs is not this clear cut as boundaries are becoming increasingly difficult to define. Recent research has emphasized the growing importance of inner suburbs as a unique geographical region with its own set of opportunities and challenges that distinguish them from the urban core and the outer suburbs. This newfound consideration of inner suburban regions is significant as in many instances urban issues that were customarily linked with city centres - high crime rates, low quality public services, deteriorating infrastructure and housing stock and higher concentrations of minority and disadvantaged households - are now being experienced in the inner suburban regions (Painter, Liu \& Zhuang, 2007). These areas are now accepting recently arrived immigrants - as is the case in Toronto - as gentrification and redevelopment raises housing prices in the urban core. As a result, many immigrants are now moving into these areas of well maintained, older housing stock that were original built for the white middle class (McLafferty and Liu, 1998).

\section{Immigrant Populations and Spatial Clustering}

Demographers have documented that immigration is often the primary driver of population growth in metropolitan regions. It is therefore important to understand the role of urban spatial structures on the economic and employment outcomes of both first and second generation immigrants compared with native born residents. In many European and North American cities, immigrant settlement patterns are largely characterized by spatial clustering. Numerous studies have revealed that immigrants tend to concentrate in particular areas of metropolitan regions according to their ethnicity and country of origin (Blázquez, Llano \& Moral, 2010). The most relevant factor in determining residential location choice amongst newly 
arrived immigrants is often proximity to more established immigrants who share similar ethnocultural backgrounds (Zavodny, 1999). This clustering trend may be indicative of existing immigrant social networks that allow new arrivals to benefit from access to information regarding housing and employment options. Consequently, residential location choice is commonly influenced by familiarity with and proximity to co-nationals until a higher level of social and labour market integration has been achieved. The formation of these ethnic enclaves has clear social and economic implications. Research into the spatial mismatch hypothesis suggests that residents of predominantly non-national neighbourhoods often experience more difficulty in securing employment, lower wages and longer commutes than those living in more affluent neighbourhoods with higher concentrations of native born residents (Blázquez, Llano \& Moral, 2010). This tendency toward higher levels of poverty and unemployment within immigrant enclaves can be partly explained by this residential segregation and the resulting geographical isolation from employment sites.

\section{The Link Between Transportation and Employment Outcomes}

Employment outcomes for immigrant groups are not only affected by distance but also by commute time and access to different modes of travel. There is a growing body of literature that considers the relationship between transportation, employment and poverty amongst visible minorities in general and immigrants in particular and the majority of studies have concluded that a lack of viable transportation options is a barrier to employment for these groups (Blumenburg and Manville, 2004). In contrast, researchers have found that access to reliable transportation is linked with an increase in job opportunities, employment stability and higher wages (Cervero, Sandoval, and Landis 2002). It is often the case that those who commute by car can often navigate the route from home to work and back with greater ease than those who rely 
on public transit, even when the trip by automobile is significantly longer. However, automobile ownership amongst poorer immigrants is much lower than average and access to a reliable vehicle can become difficult (Blumenburg and Manville, 2004).

Overall commute distance tends to be positively correlated with income and in many cases higher earnings precede longer commutes. Conventional location theory suggests that many well paid workers living in the core will eventually choose to live in the suburbs even if they are employed in the central city. This decision reflects the desire for more housing and land which costs less in the outlying areas of metropolitan regions (Simpson, 1992). Access to residential amenities such as quality schools, parks and green space can also influence the decision to move to the suburbs as well when these facilities are found lacking in urban areas. Finally, higher income allows for greater access to a dependable vehicle that reduces much of the inherent cost and inconvenience of long distance commutes. As a result, low income workers tend to travel shorter distances to work while those with higher earnings tend to have longer commutes (Murikami and Young, 1997). A recent study has shown that low-income households take 20 percent fewer trips and travel 40 percent fewer miles than middle and upper income households (Loveless, 1999). However, a shorter commuting distance does not necessarily entail a shorter commute time. Travel times over short distances may still be quite long, especially when one is relying on an inefficient public transit service. Even in cities with well-organized public transport, travel times are on average much longer for transit riders than for automobile users when taking into account walking to and from stops, transferring routes and frequent vehicle stops along the way (McLafferty and Preston, 1997). 


\section{The Role of Public Transit}

Public transit in larger metropolitan areas is most efficient within the urban core and for radial connections linking the suburbs to the centre yet most suburban origin-destination pairs are difficult to achieve within a reasonable amount of time (Korsu and Wengelski, 2010). In these situations the private automobile fares much better and is far more competitive (Orfeuil, 2004). Public transport often has difficulty in overcoming spatial barriers to employment because the mass suburbanization and decentralization of jobs observed in North American cities has resulted in transit agencies having to contend with expanding service, decreased patronage and suburb to suburb commutes. In addition, the most efficient transit service has been geared towards commuters making trips from suburban areas to the centre or within the centre itself and not outwards towards the suburbs or within suburban areas exclusively (Loveless, 1999).

In cities known for comprehensive transit systems as well as those where there is a greater reliance on the private automobile, research has shown that car ownership plays a critical role in the employment outcomes of poor and immigrant populations alike (Blumenburg and Manville, 2004). Several studies have concluded that automobile ownership is a more powerful determinant in both job seeking and job retention than public transit usage and that it also correlates positively with hours worked per week and mean monthly earnings (Cervero, Sandoval, and Landis 2002; Blumenburg and Manville, 2004). Many of the advantages that the automobile retains over public transit are structural and hence related to issues of land use and governance. Perhaps the simplest explanation for the superiority of the automobile over other forms of travel for employment outcomes is that the North American urban landscape is designed around cars and has been for the past 60 years. In this sense the efficiency of cars and 
the relative ineffectiveness of transit spring from the same source. Land use and zoning policies have pushed residences farther away from the urban core while motorists have been subsidized with free parking, fuel rebates and extensive freeway systems (Wachs and Taylor, 1998). Under these conditions, the private automobile will almost always travel at higher speeds and with greater convenience than all other modes.

\section{Spatial Structure and Demographics of the Toronto Census Metropolitan Area}

The Toronto Census Metropolitan Area is a sprawling region located in Southern Ontario with an estimated population of $5,113,149$ and a land area of $5,903.63 \mathrm{~km}^{2}$ (Statistics Canada, 2007). Within the census metropolitan area there are 22 municipalities and five census subdivisions - Toronto, Durham, York, Peel, and Halton (see Map 1). According to the 2006 census, 2,503,281 people live in the city of Toronto proper, accounting for approximately half of the population in the region (Statistics Canada, 2007).

The Toronto Census Metropolitan Area is an important immigrant destination. This is reflected in recent demographic statistics which illustrate that $45.7 \%$ of the population were born outside of Canada while $8.8 \%$ of the population are considered recent immigrants (Statistics Canada, 2007). As Maps 2 and 3 illustrate, the outlying regions of the metropolitan area tend to have fewer immigrants while higher populations are observed in the former municipalities of Scarborough and Etobicoke as well as in Markham, Brampton and Mississauga. The largest visible minority groups in the region are South Asians (13.5\%), Chinese (9.6\%), Blacks (6.9\%) and Filipinos (3.4\%) (Statistics Canada, 2007). 
The median household income for the Toronto Census Metropolitan Area is $\$ 64,128$ (Statistics Canada, 2007). The majority of the most impoverished neighbourhoods are located within the city of Toronto proper, with large concentrations in Scarborough and west of the downtown core (See Map 4). More affluent areas can be found throughout the CMA mostly in the outer suburbs. It is interesting to note that while the geographies of household income and immigration are not co-terminous, there is a very high degree of similarity with many of the neighbourhoods experiencing high rates of immigrant residence also being some of the poorest in the region.

Employment density, measured in jobs per hectare, is at its peak within the city of Toronto in the downtown core and along mass transit corridors. There are also pockets of high density employment in southern York Region, Mississauga and Brampton (See Map 5). Many of these employment rich areas are located near higher concentrations of immigrants and recent immigrants while others are accessible by some of the more efficient public transit modes in the region. However, unemployment rates tend to be quite high in neighbourhoods with larger concentrations of immigrants. Map 6 illustrates where sectors of high and low unemployment are located throughout the Toronto Census Metropolitan Area. Within the city of Toronto, the former municipality of Scarborough appears to be hardest hit, while areas to the west and northwest of the downtown core also appear to have high unemployment levels.

While mapping these socio-demographic indicators is helpful in understanding where relationships lie, the following section will attempt to detail these associations further through cross tabulation in an attempt to underscore these and other correlations more explicitly. 


\section{Statistical Analysis - Cross Tabulation}

The following section will employ the statistical method of cross tabulation to help determine the relationship between immigration status and a number of explanatory variables. Further, this analysis will examine the connection between mode choice for work related trips and distance to work with various socioeconomic factors for the Toronto Census Metropolitan Area. Data extracted from the 2006 census and public use microdata files will be used throughout this investigation.

The first set of cross tabulations employed census tract level data. The following six variables and their abbreviations were used in STATA version 9.0, a general purpose statistical software package, to conduct the analysis. For each variable, a value of 1,2 or 3 was given indicating whether the value for that particular census tract fell in the lower third (1), middle third (2) or upper third (3) for that category. There were 999 census tracts in the data set meaning that each of the five variables was divided into three equal groups of 333 as detailed above.

1. TransCrs - Details whether a census tract fell within the lower, middle or upper third for percentage of work trips made by transit

2. CarOvCrs - Details whether a census tract fell within the lower, middle or upper third for percentage of work trips made by automobile as either a driver or a passenger

3. PerImm Cr - Details whether a census tract fell within the lower, middle or upper third for percentage of residents who are immigrants

4. PeReImCr - Details whether a census tract fell within the lower, middle or upper third for percentage of residents who are recent immigrants

5. MedInCr - Details whether a census tract fell within the lower, middle or upper third for median household income 
6. UnempCrs - Details whether a census tract fell within the lower, middle or upper third for percentage of residents who are unemployed

Six separate cross tabulations were conducted with TransCrs and CarOvCrs as the row or dependent variables and the other four indicators acting as the column or independent variables. Another three cross tabulations examined the relationship between median household income, percentage of immigrant and recent immigrants and unemployment rate. Every cross tabulation denoted a statistically significant relationship according to the Pearson chi-square test.

\section{Cross Tabulation 1}

The first cross tabulation examines the relationship between TransCrs (the percentage of work trips made by transit) and PerImmCr (the percentage of residents who are immigrants).

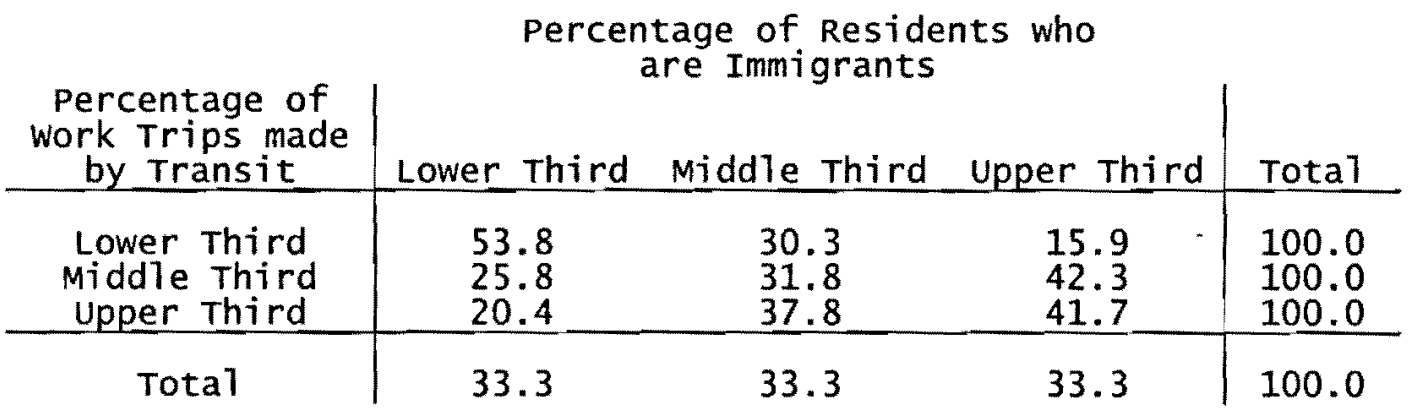

This analysis highlights some very interesting trends. $53.8 \%$ of census tracts in the lower third for transit ridership were also in the lower third for percentage of immigrant residents while only $15.9 \%$ of those census tracts within that same transit ridership bracket were in the upper third for immigrant residency. At the other end of the spectrum, only $20.4 \%$ of those in the upper third for transit ridership were in the lower third for immigration rates while $41.7 \%$ of those census tracts 
with the highest transit ridership also had the highest concentration of immigrants. These figures show generally that as the concentration of immigrants increases so does transit patronage.

\section{Cross Tabulation 2}

The second cross tabulation examines the relationship between TransCrs (the percentage of work trips made by transit) and PeReImCr (the percentage of residents who are recent immigrants).

\begin{tabular}{|c|c|c|c|c|}
\hline \multirow{2}{*}{$\begin{array}{c}\text { Percentage of } \\
\text { work Trips made } \\
\text { by Transit }\end{array}$} & \multicolumn{3}{|c|}{$\begin{array}{l}\text { Percentage of Residents who } \\
\text { are Recent Immigrants }\end{array}$} & \multirow[b]{2}{*}{ Total } \\
\hline & Lower Third & Middle Thirc & Upper Third & \\
\hline $\begin{array}{l}\text { Lower Third } \\
\text { Middle Third } \\
\text { Upper Third }\end{array}$ & $\begin{array}{l}58.3 \\
23.4 \\
18.3\end{array}$ & $\begin{array}{l}27.9 \\
38.1 \\
33.9\end{array}$ & $\begin{array}{l}13.8 \\
38.4 \\
47.7 \\
\end{array}$ & $\begin{array}{l}100.0 \\
100.0 \\
100.0\end{array}$ \\
\hline Total & 33.3 & 33.3 & 33.3 & 100.0 \\
\hline
\end{tabular}

The disparities present in this second analysis are even more pronounced than in the first. $58.3 \%$ of those census tracts with the lowest transit ridership also fell into the lowest category for percentage of recent immigrants. Conversely, $47.7 \%$ of those census tracts with the highest transit ridership also had the highest population of recent immigrants.

\section{Cross Tabulation 3}

The third cross tabulation examines the relationship between TransCrs (the percentage of work trips made by transit) and $\mathrm{MedInCr}$ (median household income). 


\begin{tabular}{c|ccc|c}
$\begin{array}{c}\text { Percentage of } \\
\text { work Trips made } \\
\text { by Transit }\end{array}$ & \multicolumn{4}{|c}{ Median Household Income } \\
\hline Lower Third & Middle Third & Upper Third & Total \\
\hline Lower Third & 7.8 & 39.9 & 52.3 & 100.0 \\
Middle Third & 32.1 & 37.8 & 30.0 & 100.0 \\
Upper Third & 60.1 & 22.2 & 17.7 & 100.0 \\
\hline Total & 33.3 & 33.3 & 33.3 & 100.0
\end{tabular}

Perhaps unsurprisingly, there appears to be a strong correlation between median household income and transit ridership in the Toronto Census Metropolitan Area. The preceding table shows that residents in census tracts with higher median incomes tend to take transit to work less while those living in lower income areas tend to take transit to work more often. This negative correlation between transit ridership and income is quite strong.

\section{Cross Tabulation 4}

The fourth cross tabulation examines the relationship between $\mathrm{MedInCr}$ (median household income) and PerImm Cr (the percentage of residents who are immigrants). It has been shown that there is a higher incidence of transit ridership in census tracts with higher concentrations of immigrants and recent immigrants as well as in those census tracts with lower median household incomes. This next cross tabulation will attempt to make the relationship between median household income and immigrant concentration that seems to follow from the first three cross tabulations more explicit and empirically driven. 
Percentage of Residents who

are Immigrants

\begin{tabular}{c|ccc|c}
$\begin{array}{c}\text { Median } \\
\text { Household } \\
\text { Income }\end{array}$ & \multicolumn{3}{|c|}{ are Immigrants } & Lower Third \\
\hline Middle Third & Upper Third & Total \\
\hline Lower Third & 3.0 & 24.6 & 72.4 & 100.0 \\
Middle Third & 24.9 & 49.8 & 25.2 & 100.0 \\
Upper Third & 72.1 & 25.5 & 2.4 & 100.0 \\
\hline Total & 33.3 & 33.3 & 33.3 & 100.0
\end{tabular}

These are perhaps the most telling findings of all. $72.4 \%$ of those census tracts in the lowest income bracket also have the highest concentrations of immigrants while only $2.4 \%$ of those census tracts in the highest income brackets have the same levels of immigrant residency. Further, $72.1 \%$ of those census tracts with the highest levels of income also have the lowest immigrant populations.

\section{Cross Tabulation 5}

The fifth cross tabulation examines the relationship between $\mathbf{M e d I n C r}$ (median household income) and PeReImCr (the percentage of residents who are recent immigrants).

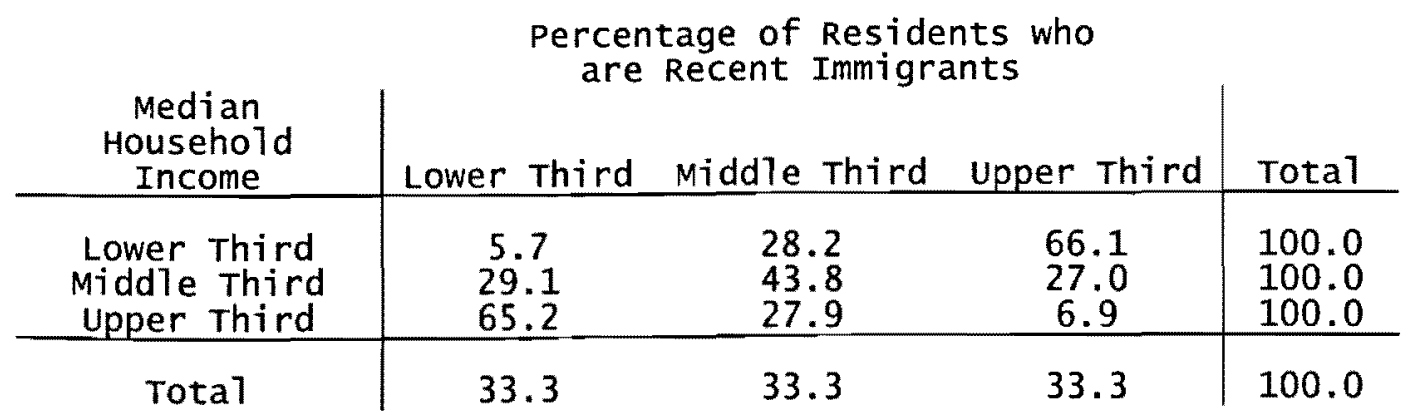


These findings are similar to those seen in the previous cross tabulation though not as drastic. The trend does continue however - more affluent areas tend to have fewer recent immigrants while poorer areas tend to have larger concentrations.

From these five cross tabulations a number of trends emerge.

1. As transit patronage increases so does the percentage of immigrants within a census tract

2. As transit patronage increases the percentage of recent immigrants within a census tract also tends to increase- this relationship is stronger than for all immigrants combined

3. As transit patronage increases in a census tract the probability of that census tract having a lower median household income also increases

4. As median household income increases the concentration of immigrants within a census tract tends to decrease - this relationship is very strong

5. As median household income increases the concentration of recent immigrants within a census tract tends to decrease as well though not as strongly as when considering the entire immigrant population

What can be gathered from these findings is that generally, both newly arrived and established immigrants tend to have lower incomes compared with non immigrants and, as a corollary, poorer households and immigrant households tend to take transit more often than more affluent non-immigrant households.

The next set of cross tabulations will explore the relationship between taking a car to work (either as a driver or a passenger), median household income and immigrant status. 


\section{Cross Tabulation 6}

The sixth cross tabulation examines the relationship between CarOvCrs (percentage of work trips made by automobile as either a driver or a passenger) and $\mathrm{MedInCr}$ (median household income).

\begin{tabular}{|c|c|c|c|c|}
\hline \multirow{2}{*}{$\begin{array}{c}\text { Percentage of } \\
\text { work Trips made } \\
\text { by Car }\end{array}$} & \multicolumn{3}{|c|}{ Median Household Income } & \multirow[b]{2}{*}{ Total } \\
\hline & Lower Third & Middle Thirc & Upper Third & \\
\hline $\begin{array}{l}\text { Lower Third } \\
\text { Middle Third } \\
\text { upper Third }\end{array}$ & $\begin{array}{r}58.0 \\
33.9 \\
8.1 \\
\end{array}$ & $\begin{array}{l}20.4 \\
40.8 \\
38.7 \\
\end{array}$ & $\begin{array}{l}21.6 \\
25.2 \\
53.2 \\
\end{array}$ & $\begin{array}{l}100.0 \\
100.0 \\
100.0 \\
\end{array}$ \\
\hline Total & 33.3 & 33.3 & 33.3 & 100.0 \\
\hline
\end{tabular}

This analysis shows that $58 \%$ of those census tracts with the lowest rates of automobile use for work trips are also in the lowest income bracket. Conversely, $53.2 \%$ of census tracts with the highest incidence of automobile use are also in the highest range for median household income. Again this is not particularly surprising, yet when combined with the information gathered from the previous five cross tabulations and the two that are to follow, one can make the case that immigrants in the Toronto Census Metropolitan Area are at a disadvantage when it comes to mobility throughout the region.

\section{Cross Tabulation 7}

The seventh cross tabulation examines the relationship between $\mathrm{CarOv} C r$ s (percentage of work trips made by automobile as either a driver or a passenger) and $\mathrm{PerImmCr}$ (the percentage of residents who are immigrants). 
Percentage of Residents who

are Immigrants

\begin{tabular}{|c|c|c|c|c|}
\hline $\begin{array}{c}\text { Percentage of } \\
\text { work Trips made } \\
\text { by Car }\end{array}$ & Lower Third & Middle Third & Upper Third & Total \\
\hline $\begin{array}{c}\text { Lower Third } \\
\text { Middle Third } \\
\text { Upper Third }\end{array}$ & $\begin{array}{l}25.8 \\
23.1 \\
51.1 \\
\end{array}$ & $\begin{array}{l}37.2 \\
33.6 \\
29.1 \\
\end{array}$ & $\begin{array}{l}36.9 \\
43.2 \\
19.8 \\
\end{array}$ & $\begin{array}{l}100.0 \\
100.0 \\
100.0 \\
\end{array}$ \\
\hline Total & 33.3 & 33.3 & 33.3 & 100.0 \\
\hline
\end{tabular}

These figures, though not as telling as those that came before, are still quite significant. $51.1 \%$ of census tracts in the upper third for automobile use are also in the lower third for concentration of immigrants. In addition, only $19.8 \%$ of census tracts with this same level of automobile use reside in areas with the highest concentration of immigrants.

\section{Cross Tabulation 8}

The eighth cross tabulation examines the relationship between $\mathrm{CarOv} C r s$ (percentage of work trips made by automobile as either a driver or a passenger) and PeReImCr (the percentage of residents who are recent immigrants)

\begin{tabular}{|c|c|c|c|c|}
\hline \multirow{2}{*}{$\begin{array}{c}\text { Percentage of } \\
\text { work Trips made } \\
\text { by Car }\end{array}$} & \multicolumn{3}{|c|}{$\begin{array}{l}\text { Percentage of Residents who } \\
\text { are Recent Immigrants }\end{array}$} & \multirow[b]{2}{*}{ Total } \\
\hline & Lower Third & Middle Third & Upper Third & \\
\hline $\begin{array}{l}\text { Lower Third } \\
\text { Middle Third } \\
\text { upper Third }\end{array}$ & $\begin{array}{l}22.5 \\
21.9 \\
55.6\end{array}$ & $\begin{array}{l}33.0 \\
36.6 \\
30.3\end{array}$ & $\begin{array}{l}44.4 \\
41.4 \\
14.1\end{array}$ & $\begin{array}{l}100.0 \\
100.0 \\
100.0\end{array}$ \\
\hline Total & 33.3 & 33.3 & 33.3 & 100.0 \\
\hline
\end{tabular}

These findings are similar to those found in cross tabulation 7 yet they show an even stronger negative correlation. $55.6 \%$ of census tracts with high automobile have the loweest recent 
immigrant populations while $44.4 \%$ of census tracts with low automobile use have higher recent immigrant populations. This shows that generally newly arrived immigrants are less likely to use a car to get to work than both immigrants as a whole and non immigrants alike. This is echoed by findings in cross tabulation 2 which show that newly arrived immigrants are more likely to use transit than all immigrants combined and Canadians.

\section{Cross Tabulation 9}

The ninth cross tabulation examines the relationship between PerImm Cr (the percentage of residents who are immigrants) and UnempCrs (the percentage of residents who are unemployed).

\begin{tabular}{|c|c|c|c|c|}
\hline $\begin{array}{l}\text { Percentage of } \\
\text { Residents who } \\
\text { are Immigrants }\end{array}$ & Lower Third & $\begin{array}{l}\text { Ige of Resic } \\
\text { e Unemploye }\end{array}$ & Upper Third & Tota1 \\
\hline $\begin{array}{l}\text { Lower Third } \\
\text { Middle Third } \\
\text { Upper Third }\end{array}$ & $\begin{array}{l}62.5 \\
28.8 \\
10.5\end{array}$ & $\begin{array}{l}27.0 \\
41.4 \\
29.1 \\
\end{array}$ & $\begin{array}{l}10.5 \\
29.7 \\
60.4 \\
\end{array}$ & $\begin{array}{l}100.0 \\
100.0 \\
100.0\end{array}$ \\
\hline Tota1 & 33.3 & 33.3 & 33.3 & 100.0 \\
\hline
\end{tabular}

This cross-tabulation illustrates that $62.5 \%$ of census tracts with the highest levels of immigrant residency also have the highest rate of unemployment while only $10.5 \%$ of these areas belong in the lowest cohort for unemployment. Only $10.5 \%$ of census tracts with lower concentrations of immigrants are in the high unemployment cohort while $60.4 \%$ of areas with higher proportions of native born Canadians experience the lowest level of unemployment.

This series of cross tabulations has built upon the results from the previous five investigations to show that: 
1. Residents in more affluent census tracts tend to take the automobile to work more often

2. Residents in areas with more concentrated immigrant populations tend to take the automobile to work less often

3. Areas with more concentrated immigrant populations tend to have higher unemployment rates as well.

The results of these nine cross tabulations, when combined, show that immigrant populations in the Toronto Census Metropolitan Area generally make less money, are more often unemployed, rely more on transit and less on the automobile to get to work than Canadian born residents.

Further, these findings show that recent immigrants rely more on transit and less on the automobile to get to work than all immigrants combined yet they make more money on average. What these statistics illustrate, when coupled with results from previous transportation studies suggesting that commute times in the Toronto area are longer when taking transit as opposed to the automobile, is that there is a commuting disadvantage for immigrants when compared with Canadians.

The second set of cross tabulations were conducted using data gathered from the 2006 Toronto Census Metropolitan Area public use microdata files. Four variables were used:

1. moderng-Mode of transportation to work

2. distrng-Commuting distance to work

3. hhincrng - Detailing whether a given response for median household income fell within one of five approximately equal ranges

4. imstatus - Immigrant status 


\section{Cross Tabulation 10}

The tenth cross tabulation examines the relationship between distrng (commuting distance to work) and imstatus (immigrant status)

\begin{tabular}{c|cc|c}
$\begin{array}{c}\text { Commuting } \\
\text { Distance to } \\
\text { Work }\end{array}$ & \multicolumn{2}{|c|}{ Immigrant status } & \\
\hline $0-5 \mathrm{~km}$ & Non-Immigrant & Immigrant & Total \\
\hline $5-10 \mathrm{~km}$ & 30.7 & 26.1 & 28.4 \\
$10-15 \mathrm{~km}$ & 21.6 & 24.9 & 23.3 \\
$15-25 \mathrm{~km}$ & 14.7 & 17.8 & 16.3 \\
$25 \mathrm{~km}+$ & 16.7 & 19.2 & 18.0 \\
Total & 16.3 & 12.0 & 14.1 \\
\hline & 100.0 & 100.0 & 100.0
\end{tabular}

This cross tabulation shows that a greater percentage of non-immigrants $(30.7 \%)$ have a commute distance of less than $5 \mathrm{~km}$ than do immigrants (26.1\%). Also, $52.3 \%$ of nonimmigrants and $51 \%$ of immigrants have a commute distance of less than $10 \mathrm{~km}$. These disparities are not as pronounced as one might have expected given the results from the first set of cross tabulations. In addition, $16.3 \%$ of Canadian born respondents experience daily commutes of longer than $25 \mathrm{~km}$ compared with only $12 \%$ of immigrants.

\section{Cross Tabulation 11}

The eleventh cross tabulation examines the relationship between distrng (commuting distance to work) and hhincrng (median household income).

This analysis illustrates that respondents with lower levels of income tend to have shorter commutes than those at higher levels. This is not to say, however, that lower income individuals necessarily have shorter commute times than wealthier individuals. These figures simply show that respondents in lower income brackets tend to live closer to work. These results are 
consistent with previous research which states that commuting distance is positively correlated with income.

\begin{tabular}{|c|c|c|c|c|c|c|}
\hline \multirow[b]{2}{*}{$\begin{array}{l}\text { Commuting } \\
\text { Distance } \\
\text { to work }\end{array}$} & \multirow[b]{2}{*}{$0-49,999$} & \multicolumn{2}{|c|}{ Household Incom } & \multicolumn{2}{|l|}{ Ranges } & \multirow[b]{2}{*}{ Total } \\
\hline & & $\begin{array}{r}50,000- \\
74,999 \\
\end{array}$ & $\begin{array}{r}75,000- \\
99,999 \\
\end{array}$ & $\begin{array}{r}100,000- \\
149,999 \\
\end{array}$ & $150,000+$ & \\
\hline $\begin{array}{c}0-5 \mathrm{~km} \\
5-10 \mathrm{~km} \\
10-15 \mathrm{~km} \\
15-25 \mathrm{~km} \\
25 \mathrm{~km}+\end{array}$ & $\begin{array}{l}35.8 \\
25.3 \\
16.0 \\
14.6 \\
8.3 \\
\end{array}$ & $\begin{array}{l}30.7 \\
24.6 \\
16.8 \\
16.7 \\
11.2\end{array}$ & $\begin{array}{l}26.8 \\
22.5 \\
16.7 \\
19.4 \\
14.6 \\
\end{array}$ & $\begin{array}{l}24.7 \\
21.4 \\
16.8 \\
19.7 \\
17.3 \\
\end{array}$ & $\begin{array}{l}23.8 \\
22.7 \\
14.9 \\
19.4 \\
19.1\end{array}$ & $\begin{array}{l}28.4 \\
23.3 \\
16.3 \\
18.0 \\
14.1\end{array}$ \\
\hline Total & 100.0 & 100.0 & 100.0 & 100.0 & 100.0 & 100.0 \\
\hline
\end{tabular}

\section{Cross Tabulation 12}

The twelfth cross tabulation examines the relationship between moderng (mode of transportation to work) and imstatus (immigration status).

\begin{tabular}{|c|c|c|c|}
\hline $\begin{array}{c}\text { Mode of } \\
\text { Transportation } \\
\text { to work }\end{array}$ & $\begin{array}{c}\text { Immigra } \\
\text { Non- } \\
\text { Immigrant }\end{array}$ & Immigrant & Total \\
\hline $\begin{array}{c}\text { Automobile } \\
\text { Transit or Taxi } \\
\text { walk or Bike } \\
\end{array}$ & $\begin{array}{l}71.1 \\
21.0 \\
8.0\end{array}$ & $\begin{array}{r}67.6 \\
27.7 \\
4.8 \\
\end{array}$ & $\begin{array}{r}69.3 \\
24.3 \\
6.4 \\
\end{array}$ \\
\hline Total & 100.0 & 100.0 & 100.0 \\
\hline
\end{tabular}

The main findings of this particular cross tabulation are that $71.7 \%$ of work related trips for nonimmigrants are taken by car compared to $67.6 \%$ for immigrants. Additionally, $27.7 \%$ of immigrant respondents take transit or a taxi to work compared to $21 \%$ of non-immigrants. Nonimmigrants are also almost twice as likely to walk or bike to work compared to immigrants. 
According to this data, immigrants are more likely to take transit to work and less likely to drive, bike or walk to work than non-immigrants.

\section{Cross Tabulation 13}

The thirteenth cross tabulation examines the relationship between moderng (mode of transportation to work) and hhincrng (median household income).

\begin{tabular}{c|ccccc|c} 
Mode of & \multicolumn{7}{c}{ Household Income Ranges } & \\
$\begin{array}{c}\text { Transportation } \\
\text { to work }\end{array}$ & $\begin{array}{c}0- \\
49,999\end{array}$ & $\begin{array}{c}50,000- \\
74,999\end{array}$ & $\begin{array}{c}75,000- \\
99,999\end{array}$ & $\begin{array}{c}100,000- \\
149,999\end{array}$ & $150,000+$ & Total \\
\hline Automobile & 54.9 & 66.2 & 71.7 & 75.6 & 78.6 & 69.3 \\
Transit or Taxi & 34.9 & 26.8 & 22.9 & 19.8 & 16.9 & 24.3 \\
Walk or Bike & 10.2 & 7.0 & 5.4 & 4.7 & 4.5 & 6.4 \\
\hline Total & 100.0 & 100.0 & 100.0 & 100.0 & 100.0 & 100.0
\end{tabular}

Similar to what was found at the census tract level, lower income individuals tend to rely more on transit, walking or biking and less on the automobile for work trips than those in the middle range. Subsequently, middle income individuals tend to rely more on transit, walking or biking and less on the automobile for work trips than those in the upper income range. This suggests a positive correlation between income and the propensity to drive to work and a negative correlation between income and the propensity to take transit, walk or bike to work.

\section{Cross Tabulation 14}

The fourteenth and final cross tabulation in this series examines the relationship between hhincrng (median household income) and imstatus (immigration status). 


\begin{tabular}{c|cc|c}
$\begin{array}{c}\text { Household } \\
\text { Income Ranges }\end{array}$ & \multicolumn{2}{|c|}{ Immigrant status } & \\
& Non-Immigrant & Immigrant & Tota1 \\
\hline $0-49,999$ & 16.3 & 26.4 & 21.4 \\
$50,000-74,999$ & 16.0 & 20.4 & 18.2 \\
$75,000-99,999$ & 17.8 & 18.2 & 18.0 \\
$100,000-149,999$ & 26.2 & 21.3 & 23.7 \\
$150,000+$ & 23.7 & 13.7 & 18.7 \\
\hline Tota1 & 100.0 & 100.0 & 100.0
\end{tabular}

These figures are just as telling as the comparable analysis that took place at the census tract level. $26.4 \%$ of immigrant respondents in the Toronto Census Metropolitan Area fall within the lowest income bracket and $13.7 \%$ in the upper income range. In contrast, $16.3 \%$ of nonimmigrants belonged to the lower income cohort while $23.7 \%$ were members of the upper income group. The middle class $(\$ 75,000-\$ 99,999)$ is quite diverse however, with roughly equal proportions of immigrants and non-immigrants being members.

Similar to the series of nine cross tabulations administered at the census tract level, a number of conclusions can be drawn from the five investigations conducted using the public use microdata files for the Toronto Census Metropolitan Area.

1. Non-immigrants tend to have slightly shorter commutes by distance than immigrants

2. Lower income individuals tend to live closer to work. However, this does not necessarily mean that they have shorter commute times

3. Immigrants are more likely to take transit to work and less likely to take a car to work than non-immigrants

4. Lower income individuals tend to take transit to work more often and take a car to work less often than higher income individuals

5. Non-immigrants tend to have higher incomes than immigrants 
These fourteen cross tabulations when taken together illustrate that there is a strong, empirically grounded case to be made for the assertion that there is a commuting penalty for immigrants in the Greater Toronto Area compared to native born Canadians. This preliminary analysis will be further supported in the next section through the use of a generalized ordered logit model which will determine the extent to which certain socio-demographic indicators affect commute distances when controlling for other factors in the Toronto Census Metropolitan Area.

\section{Econometric Analysis}

In past studies, the spatial mismatch hypothesis has been tested using a variety of outcome measures - commute distance, commute time, job accessibility and employment ratios to name a few - while the range of explanatory variables employed in these investigations is even more varied. Further, when testing for spatial mismatch in a given region, the availability and limitations of specific datasets will often influence the choice of dependent and independent variables. A thorough investigation of past literature and applicable datasets is therefore essential when formulating econometric models to explain spatial mismatch.

In this study, the 2006 census public use microdata file, which contains data based on a sample that represents approximately $2.7 \%$ of the Canadian population, was used to conduct econometric analysis. The strength of this census product is that it provides non-aggregated data across 123 variables and a large sample size (the Toronto Census Metropolitan Area alone having 137,290 respondents) (Statistics Canada, 2010). This comprehensive tool allows users to group and manipulate variables and estimate regression models that can test for a variety of research questions, including the spatial mismatch hypothesis. 
Within this dataset there are several variables that could be used as both response and predictor variables when testing for spatial mismatch in the Toronto CMA. These options can be cross-referenced with previous studies to determine which factors to include when constructing a suitable econometric model. Table 1 (see appendix) illustrates the specific indicators that have been included in prior investigations. The selected studies have either been referred to previously in the literature review section of this paper or figure heavily in other treatments of the spatial mismatch hypothesis.

The most common outcome variables in the literature are commute distance, commute time and some measure of employment ratio or status. Selecting one or more of these three variables is largely contingent upon whether one is interested primarily in investigating employment outcomes or commuting patterns. This study is more so concerned with immigrant commuting patterns and so the option for a suitable dependent variable is narrowed down to either commute distance or commute time. Commute time does not appear as a variable within the 2006 census public use microdata file and as a result, commute distance will serve as the outcome variable for econometric analysis of spatial mismatch in the Toronto Census Metropolitan Area.

The majority of the explanatory variables in Table 1 appear in the 2006 census public use microdata file - the most notable exceptions are commute time and some form of geographic indicator more detailed than metropolitan area. Age, sex, nationality/ethnicity, level of education and housing type/marital status figure prominently in the majority of the selected studies. However, this paper is not concerned with a particular subset of immigrants from specific regions of the world, but rather with the commuting patterns of all immigrants of working age. For this reason a nationality or race indicator has been omitted. A household living arrangement 
variable was also excluded because there is no indication in the public use microdata files of whether male and female married and common-law partners also have children. The remaining three variables, age, sex and level of education, were included in the final econometric model.

Mode of travel was included in the public use microdata file but its relationship to commute distance is somewhat self-explanatory - as commute distances increase so does the likelihood that a respondent will travel to work by car. It has more explanatory power when considering employment ratios or status as the dependent variable. Modal choice was therefore left out of the final analysis in favour of a more parsimonious model. Another variable that appeared in numerous studies was a car ownership indicator, however it did not appear in the microdata file and so could not be used in this particular instance.

Housing tenure was included as an explanatory variable within this model as previous studies have shown that the discrepancies between the commuting patterns of homeowners and renters can be quite pronounced. Accordingly, household size was also included as a predictor in the final model as it often plays an important role in residential choice. Another socio-economic indicator that was incorporated into the final model was median household income. This variable appears in a number or prior investigations and its relationship with commute distance has been well documented.

Three variables related to immigration that appear in the literature and in the public use microdata files were also considered - immigrant status (a binary indicator denoting whether a respondent was an immigrant or not), immigrant generation status and length of residence in the host country. Each of these three variables had a high degree of correlation with the other two so only one could be chosen for the final analysis. Ultimately, length of residence in Canada was 
included in the model because it explained more of the variance in commuting distance than the simple binary variable for immigrant status and generated results that were more significant, parsimonious and interpretable than those produced using generation status. Table 2 (see appendix) provides the definition of variables included in the final econometric analysis.

To begin, an ordered logit model was estimated as the dependent variable, commute distance, is an ordered discrete variable. Ordered regression models assume parallel regression curves across different ordered responses (Kweon and Lee, 2010). This prerequisite condition, also known as the proportional odds assumption, is often violated when conducting ordered regression analysis. It is therefore imperative that this assumption be tested for the proposed model.

- ologit distrng timecan hisize hidegree hincrng tenur sex agegrps

Iteration 0: log likelihood $=-99419.273$

Iteration 1: log likelihood $=-\mathbf{9 7 8 7 2 . 9 1 4}$

Iteration 2: log likelihood $=\mathbf{- 9 7 8 6 9 . 8 9 7}$

Iteration 3: $\log$ likelihood $=\mathbf{- 9 7 8 6 9 . 8 9 7}$

ordered logistic regression

$\log 11$ ke1 thood $=-97869.897$

$\begin{array}{llr}\text { Number of obs } & = & 63021 \\ \text { LR ch1 } 2(7) & = & 3098.75 \\ \text { Prob }>\text { chi2 } & = & 0.0000 \\ \text { Pseudo R2 } & = & 0.0156\end{array}$

\begin{tabular}{|c|c|c|c|c|c|c|}
\hline distrng & coef. & std. Err. & $\mathbf{z}$ & $P>|z|$ & [95\% conf. & Interval] \\
\hline $\begin{array}{r}\text { timecan } \\
\text { hhstze } \\
\text { hidegree } \\
\text { hhincrng } \\
\text { tenur } \\
\text { sex } \\
\text { agegrps }\end{array}$ & $\begin{array}{r}-.0077011 \\
-.0088372 \\
.0862141 \\
.1045732 \\
.4347145 \\
.3531805 \\
.1225455\end{array}$ & $\begin{array}{l}.0046086 \\
.0055329 \\
.0045731 \\
.0060919 \\
.0185444 \\
.0142851 \\
.0080861\end{array}$ & $\begin{array}{l}-1.67 \\
-1.60 \\
18.85 \\
17.17 \\
23.14 \\
24.72 \\
15.16\end{array}$ & $\begin{array}{l}0.095 \\
0.110 \\
0.000 \\
0.000 \\
0.000 \\
0.000 \\
0.000\end{array}$ & $\begin{array}{r}-.0167338 \\
-.0196814 \\
.077251 \\
.0926334 \\
.3983681 \\
.3251822 \\
.1066971\end{array}$ & $\begin{array}{r}.0013316 \\
.002007 \\
.0951772 \\
.1165131 \\
.4710609 \\
.3811788 \\
.138394\end{array}$ \\
\hline $\begin{array}{l}\text { /cut1 } \\
\text { /cut2 } \\
\text { /cut3 } \\
\text { /cut4 }\end{array}$ & $\begin{array}{l}1.175809 \\
2.203373 \\
2.909129 \\
3.995273\end{array}$ & $\begin{array}{r}.05002 \\
.0505034 \\
.0510391 \\
.052148\end{array}$ & & & $\begin{array}{l}1.077772 \\
2.104388 \\
2.809094 \\
3.893065\end{array}$ & $\begin{array}{l}1.273847 \\
2.302358 \\
3.009164 \\
4.097482\end{array}$ \\
\hline
\end{tabular}

A Brant test was then conducted to determine whether the proposed model had violated the proportional odds assumption. 
- brant, detail

Estimated coeffictents from j-1 binary regressions

\begin{tabular}{|c|c|c|c|c|}
\hline $\begin{array}{r}\text { timec } \\
\text { hhsi } \\
\text { hidegr } \\
\text { hincr } \\
\text { ten } \\
\text { s } \\
\text { agegr } \\
\text { _co }\end{array}$ & $\begin{array}{r}.0 \\
.1 \\
.3 \\
.3 \\
.1 \\
-.9\end{array}$ & $\begin{array}{r}y \\
-.0112910 \\
-.0025397 \\
.082245 \\
.089306\end{array}$ & $\begin{array}{r}- \\
: \\
:\end{array}$ & - \\
\hline
\end{tabular}

Brant Test of Parallel Regresston Assumption

\begin{tabular}{r|rrr} 
vartable & ch12 & $p>c h 12$ & df \\
\hline A11 & $\mathbf{7 2 9 . 5 5}$ & $\mathbf{0 . 0 0 0}$ & $\mathbf{2 1}$ \\
\hline timecan & $\mathbf{2 8 4 . 1 7}$ & $\mathbf{0 . 0 0 0}$ & 3 \\
hhsize & $\mathbf{7 . 6 8}$ & $\mathbf{0 . 0 5 3}$ & 3 \\
hidegree & $\mathbf{1 1 . 9 8}$ & $\mathbf{0 . 0 0 7}$ & 3 \\
hhincrng & $\mathbf{2 1 . 6 3}$ & $\mathbf{0 . 0 0 0}$ & 3 \\
tenur & $\mathbf{8 9 . 9 0}$ & $\mathbf{0 . 0 0 0}$ & 3 \\
sex & $\mathbf{1 9 . 9 0}$ & $\mathbf{0 . 0 0 0}$ & $\mathbf{3}$ \\
agegrps & $\mathbf{1 1 5 . 7 9}$ & $\mathbf{0 . 0 0 0}$ & $\mathbf{3}$ \\
\hline
\end{tabular}

A stgnificant test statistic provides evfdence that the parallel regression assumption has been violated.

All but one of the explanatory variables produced a significant test statistic for the Brant test indicating that the assumptions of the parallel lines model have been violated. An ordered logistic regression may therefore lead to incorrect, incomplete or misleading results (Williams, 2006). There are several options available when this occurs. A non-ordinal alternative such as the multinomial logistic regression model may be employed as this method relaxes the proportional odds assumption for all explanatory variables. However, the drawback of this model is that it discounts the intrinsic ordering of the outcome measure. Another option involves estimating a generalized ordered logit model that relaxes the proportional odds assumption for some or all of the explanatory variables. These models are often more parsimonious and interpretable when compared with multinomial logistic regressions, while retaining the natural ordering of the outcome variable (Williams, 2006). 
In order to properly estimate a generalized logit model, it is crucial to know which explanatory variables violate the proportional odds assumption. If there are variables which do not violate this condition then a partial proportional odds model may be estimated. This allows the parallel lines constraint to be relaxed only for those variables where it is not justified in a traditional ordered logit model (Williams, 2006).

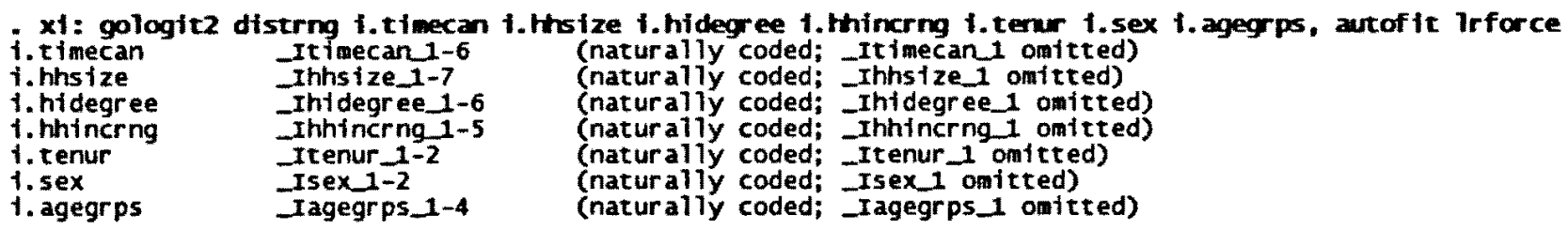

According to this output, the proportional odds assumption will be relaxed for eleven categories within the seven explanatory variables. Consequently, the constraints for the parallel lines test will be imposed for the remaining fourteen categories as they would in a traditional ordered logit model. The proposed generalized ordered logistic regression will therefore be a 
partial proportional odds model. It is this model that will be used to conduct econometric analysis for commute distance in the Toronto Census Metropolitan Area.

\section{Results of the Generalized Ordered Logistic Regression}

\begin{tabular}{|lr|}
\hline \multicolumn{2}{|c|}{ Model fit } \\
\hline Observations & 63021 \\
Log.LH & -96900.0 \\
Chi. SQR & 5112.0 \\
AlC & 194000.0 \\
\hline
\end{tabular}

\begin{tabular}{|c|c|c|c|c|c|}
\hline Base & Variable & $0-5 \mathrm{~km}$ & $5-10 \mathrm{~km}$ & $10-15 \mathrm{~km}$ & 15-25 km 25-plus km \\
\hline $0-5$ years & $5-10$ years in Canada & 1.063 & & & \\
\hline \multirow[t]{4}{*}{ in Canada } & $10-15$ years in Canada & 1.019 & & & \\
\hline & $15-20$ years in Canada & $1.076^{*}$ & & & \\
\hline & $20+$ years in Canada & 1.003 & $1.099^{* *}$ & $1.171^{* * *}$ & $1.319 * * *$ \\
\hline & canadian born & $0.814^{* * *}$ & 0.991 & $1.141^{* * *}$ & $1.549^{* * *}$ \\
\hline \multirow[t]{6}{*}{ one person } & two persons & $1.219^{* * *}$ & $1.207^{* * *}$ & $1.245^{* * * *}$ & $1.317^{* * *}$ \\
\hline & three persons & $1.237^{* * *}$ & $1.231^{* * *}$ & $1.267^{* * *}$ & $1.348 * * *$ \\
\hline & four persons & $1.200^{* * *}$ & & & \\
\hline & five persons & $1.149 * * *$ & & & \\
\hline & six persons & $1.123^{* *}$ & & & \\
\hline & seven or more persons & 1.091 & & & \\
\hline \multirow[t]{5}{*}{ none } & high school or equivalency & $1.373^{* * * *}$ & & & \\
\hline & trades or apprenticeship certificate & $1.510^{* * *}$ & & & \\
\hline & college certificate or diploma & $1.706^{* * *}$ & & & \\
\hline & university undergraduate & $1.593^{* * *}$ & & & \\
\hline & post baccalaureate degree & $1.400^{* * *}$ & $1.310^{* * *}$ & $1.312^{* * *}$ & $1.414^{* * *}$ \\
\hline \multirow[t]{4}{*}{$0-49,999$} & $50,000-74,999$ & $1.122^{* * *}$ & & & \\
\hline & $75,000-99,999$ & $1.322^{* * *}$ & & & \\
\hline & $100,000-149,999$ & $1.458^{* * *}$ & & & \\
\hline & $150,000+$ & $1.541^{* * * *}$ & $1.412^{* * *}$ & $1.518^{* * *}$ & $1.602^{* * *}$ \\
\hline rented & owned & $1.406^{* * * *}$ & $1.547^{* * *}$ & $1.697^{* * *}$ & $2.003^{* * *}$ \\
\hline female & male & $1.409^{* * *}$ & $1.441 * * *$ & $1.485^{* * *}$ & $1.575^{* * *}$ \\
\hline \multirow[t]{4}{*}{$15-24$} & $25-39$ & $1.941^{* * *}$ & $1.760^{* * * *}$ & $1.652^{* * *}$ & $1.384 * * *$ \\
\hline & $40-54$ & $1.953^{* * *}$ & $1.734^{* * *}$ & $1.645^{* * *}$ & $1.431^{* * *}$ \\
\hline & 55-64 & $1.560^{* * * *}$ & $1.412^{* * *}$ & $1.354^{* * *}$ & $1.136^{*}$ \\
\hline & Constant & $0.518^{* * *}$ & $0.168^{* * *}$ & $0.071^{* * *}$ & $0.018^{* * *}$ \\
\hline \multicolumn{6}{|c|}{ legend: * p<0.05; ** p<0.01; *** p<0.001 } \\
\hline
\end{tabular}


For a more intuitive understanding of the results, coefficients are presented in terms of odds ratios. An odds ratio of greater than 1 for a particular category means that higher values of the dependent variable are more likely to occur when compared with the reference category. Conversely, an odds ratio of less than 1 for a particular category means that higher values of the dependent variable are less likely to occur when compared with the reference category. Several variables will have the same odds ratio across the different distance categories, implying proportional odds, while others will differ across distance categories. Additionally, there will be categories within an explanatory variable that will not differ significantly with regard to commuting distance when compared with the reference category.

When comparing the commuting patterns of immigrants and Canadians in the Toronto Census Metropolitan Area, the reference group is taken to be those immigrants who have been living in Canada for less than 5 years. Econometric analysis illustrates that immigrants living for 5 to 10 years and 10 to 15 years in Canada are not significantly more likely to experience longer commutes when compared with recent immigrants. Put another way, when all other factors are controlled for in this model, immigrants living in Canada for 15 years or less have relatively similar commuting distances. This may be partly explained by the phenomenon of spatial clustering in the Toronto CMA, where less established immigrants tend to concentrate in particular areas of metropolitan regions according to their ethnicity and country of origin.

Immigrants who have been living in Canada for 15 to 20 years are approximately $8 \%$ more likely to experiencing longer commutes compared to recent immigrants. This same estimate occurs across all distance categories meaning that the odds of these more established immigrants having longer commutes will not change regardless of the length of commute being tested. Those who have been in Canada for 20 years or more share similar commuting patterns to 
recent immigrants when considering trips of over 5 kilometres yet they approximately $10 \%, 17 \%$ and $32 \%$ more likely to make trips of over 10,15 and 25 kilometres respectively.

Canadian born residents of the Toronto CMA are approximately $19 \%$ less likely to have commutes of over 5 kilometres compared to recent immigrants. In other words, recent immigrants make more commutes of over 5 kilometres than Canadian nationals. This trend, however, begins to shift when considering longer work tips. Canadians and recent immigrants share a similar predilection for commutes of over 10 kilometres while the former group is $14 \%$ and $55 \%$ more likely to travel over 15 and 25 kilometres to work respectively according to this model. This last statistic in particular is quite telling, perhaps statistically demonstrating the tendency of wealthier Canadians to relocate to suburban regions in search of more housing and land once longer commutes can be negotiated more effectively.

These results show that a higher proportion of Canadian born residents in the Toronto CMA live very close or very far away from work when compared with recent immigrants. Certain types of disadvantage in both the housing and labour markets commonly experienced by immigrants may account for these discrepancies (Blázquez, Llano \& Moral, 2010). Wealthier Canadians often have greater access to homes closer to potential employment while also possessing the means to navigate greater distances more easily. Conversely, recent immigrants in the Toronto CMA are more reliant on public transit and are often tied to specific neighbourhoods inhabited by co-nationals.

When comparing the effect that household size has on commuting distance the reference category is taken to be the single person household. In general, this model shows that households with two or more people tend to have longer commutes across all distance categories. This 
coincides with spatial mismatch literature which states that single individuals tend to consume less housing and rent more often than members of the upper cohorts while being less restricted in their housing options (Blázquez, Llano \& Moral, 2010). Regression analysis also suggests that members of three person households experience the longest commutes when controlling for all other explanatory factors within the model. In many instances, these households would be comprised of a young couple and their child. If this trend were to hold in future studies for the Toronto CMA, further research may be warranted to explain this phenomenon. Additionally, households with 4 to 6 persons tend to have longer commutes than single individuals though these odds decrease as family size increases. Interestingly enough, the commuting patterns of single individuals and members of the largest households do not vary significantly.

When considering the education level of respondents, those who have not obtained a degree, certificate or diploma were considered as the reference group. In each case, a higher level of education compared to the reference group resulted in longer commutes. College graduates experienced the longest work trips out of any cohort and were approximately $70 \%$ more likely to live further away from work than the least educated group according to this model. In addition, high school graduates, trades workers and undergraduate degree holders were $37 \%, 51 \%$ and $59 \%$ more likely to commute across longer distances. The odds that a person who had completed their post-baccalaureate education would travel further to work than a member of the least educated group was anywhere between $31 \%$ and $41 \%$.

The reference group when considering median household income was the $0 \$-\$ 49,999$ cohort. In all cases, the higher the median household income, the higher the odds of experiencing longer commutes. These findings are consistent with the spatial mismatch literature which suggests that higher earnings often precede longer commutes and that residents in search of more 
housing and land in the suburbs are willing to travel further to work. This relationship is best exemplified when considering that members of households making over $\$ 150,000$ a year are $60 \%$ more likely to travel $25 \mathrm{~km}$ or more to work than members of households making less than $\$ 50,000$ a year. Conversely, higher income cohorts are between $12 \%$ and $54 \%$ more likely to travel 5 or more kilometres to work every day highlighting the inability of many lower income individuals to negotiate longer commutes, thereby limiting employment opportunities.

The largest discrepancies within the generalized order logit model can be found when contrasting the commuting patterns of renters and owners. Homeowners are approximately $41 \%$ more likely to have commutes of over $5 \mathrm{~km}, 55 \%$ more likely to have commutes of over $10 \mathrm{~km}$, $70 \%$ more likely to have commutes of over $15 \mathrm{~km}$ and approximately twice as likely to have commutes of over 25 kilometres than renters. This trend is reflected in previous research on spatial mismatch which suggests that those renting accommodations are often unconstrained by family obligations and can therefore choose to live closer to work (Cervero, Sandoval, and Landis 2002). It is also important to note, however, that the majority of renters are in the lower income brackets and therefore experience more difficulty commuting over long distances. In contrast, homeownership is often preceded by higher incomes and becomes a consideration as a family takes on new members (Simpson, 1992). In this sense, proximity to work becomes less of a priority as the need for additional space and the ability to carry out longer commutes increases.

Econometric analysis also suggests that men are much more likely to experience longer commutes than woman. Men are approximately $41 \%$ more likely to have commutes of over 5 kilometres, $44 \%$ more likely to have commutes of over 10 kilometres, $49 \%$ more likely to have commutes of over 15 kilometres and $58 \%$ more likely to have commutes of over $25 \mathrm{~km}$ when controlling for all other variables. In addition, 25 to 39 year olds and 40 to 54 year olds have 
similar commuting patterns when compared with the youngest age cohort. The odds of 25 to 54 year olds travelling 5 or more kilometres to work are almost twice that of 15 to 24 year olds. These older residents are also more likely to experience commutes of over 10,15 and 25 kilometres though this discrepancy decreases as one increases commuting distance. This relationship is repeated for 55 to 64 year olds, however, odds ratios are not as pronounced as in previous cases.

\section{Conclusion}

This study aimed to test the spatial mismatch hypothesis, using a variety of methods, for the Toronto Census Metropolitan Area. The geography and spatial distribution of immigrants, income groups and employment was first considered followed by a series of cross tabulations that sought to uncover the relationships between a number of socioeconomic indicators. A generalized ordered logit model was then estimated to determine whether immigrants are more likely to experience longer commuting distances than Canadian born residents.

The Toronto Census Metropolitan Area, like many city-regions in North America, is characterised by the spatial clustering of its immigrant population. Research into the spatial mismatch literature has illustrated that residents of these predominately immigrant neighbourhoods often experience more difficulty in securing and maintaining employment and lower wages in general when compared to native born residents (Blázquez, Llano \& Moral, 2010). This trend holds true in the Toronto CMA as cross tabulations and mapping have shown that areas with more concentrated immigrant populations tend to have higher unemployment rates and lower median household incomes. This correlation can, to some extent, be explained by 
the residential segregation away from employment opportunities that often results from spatial clustering.

Researchers have also found that access to a reliable and efficient means of travel is positively correlated with employment outcomes. Those who commute by car can often navigate the route to work more easily than those who rely on public transit even when the route travelled by automobile is significantly longer. The mass suburbanization of population and employment experienced in North American cities, including Toronto, has put a strain on municipal and regional transit systems that has decreased efficiency in many cases. As a result, commute times for transit riders are generally much longer than for automobile users. This study has shown that immigrants in the Toronto CMA are more likely to take transit and less likely to drive to work than non-immigrants and are therefore more prone to experiencing the commuting penalties associated with taking public transit over long distances.

The generalized ordered logit model illustrates that the commuting distances for immigrants who have been living in Canada for less than 15 years do not vary significantly while those who have been in the country for 15 to 20 years experience slightly longer commutes across all distance categories. Established immigrants who have been living in Canada for 20 years or more tend to have commuting patterns that more closely resemble Canadian born residents. Regression analysis and cross tabulation has also demonstrated that Canadians are more likely to live within 5 kilometres of work and experience commutes of 15 kilometres or more. This suggests that wealthier Canadians often outbid immigrants for homes in close proximity to urban employment centres and at the suburban fringes of the metropolitan area. This results in a higher percentage of immigrants having to negotiate commutes in the middle distance ranges, an obligation that, on average, they cannot accomplish as easily as Canadian 
born residents for reasons mentioned previously. Canadians in turn benefit from living closer to work in some instances and being able to negotiate longer commutes more readily in others.

These findings, when taken together, make a strong case for the assertion that immigrants are at a commuting disadvantage when compared with Canadian born residents in the Toronto Census Metropolitan Area. 


\section{Appendix A - Maps}

Map 1

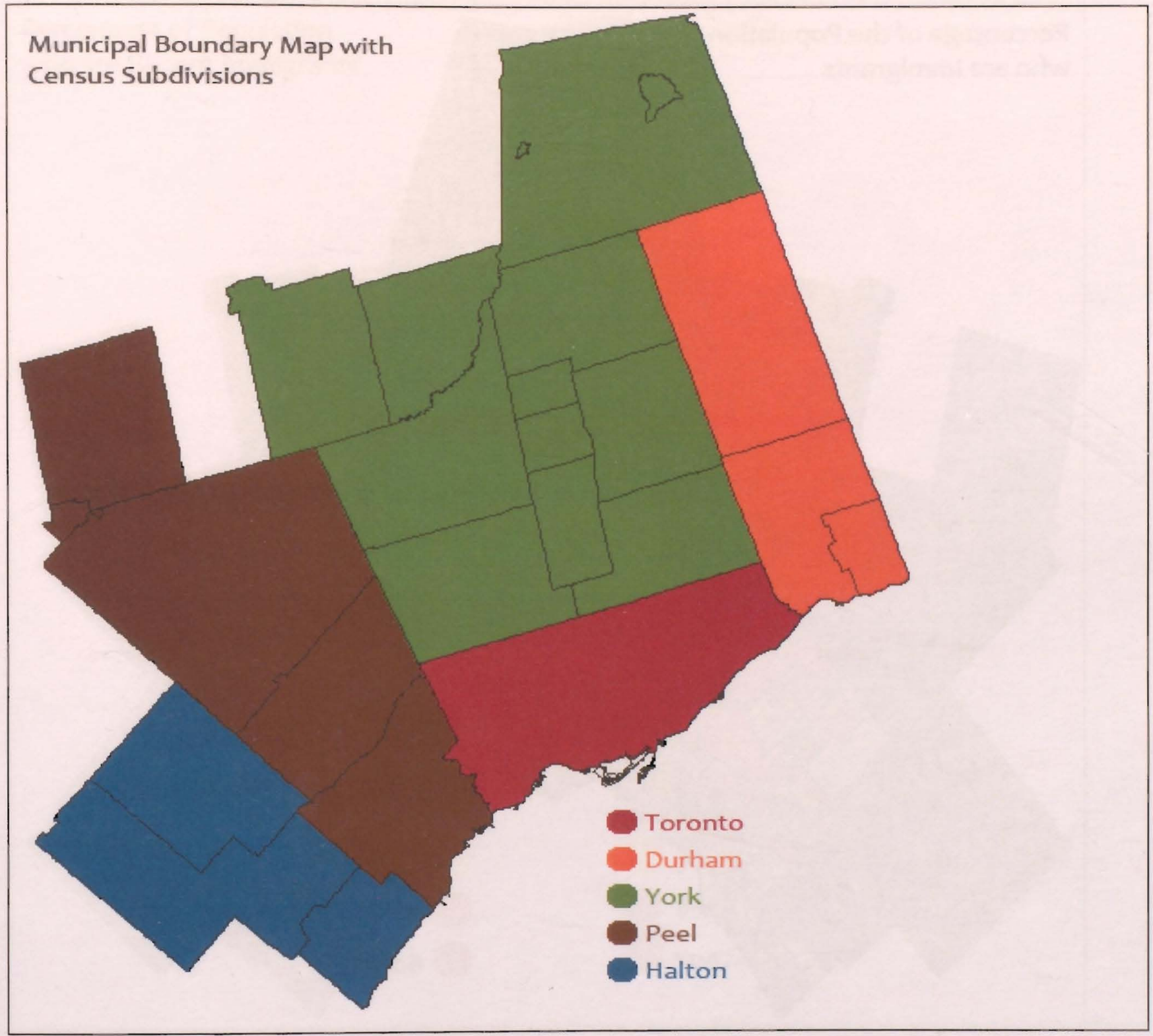


Map 2

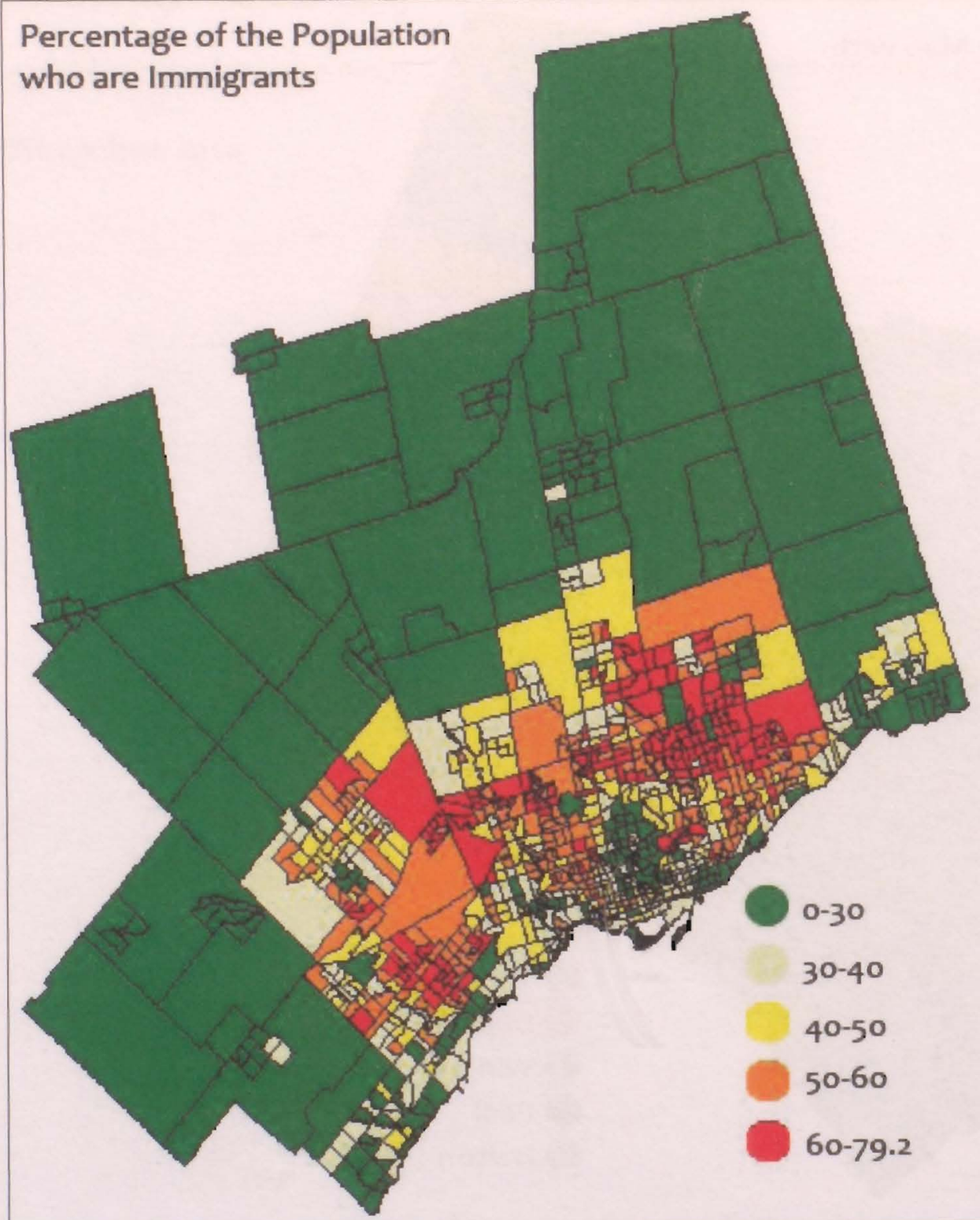


Map 3

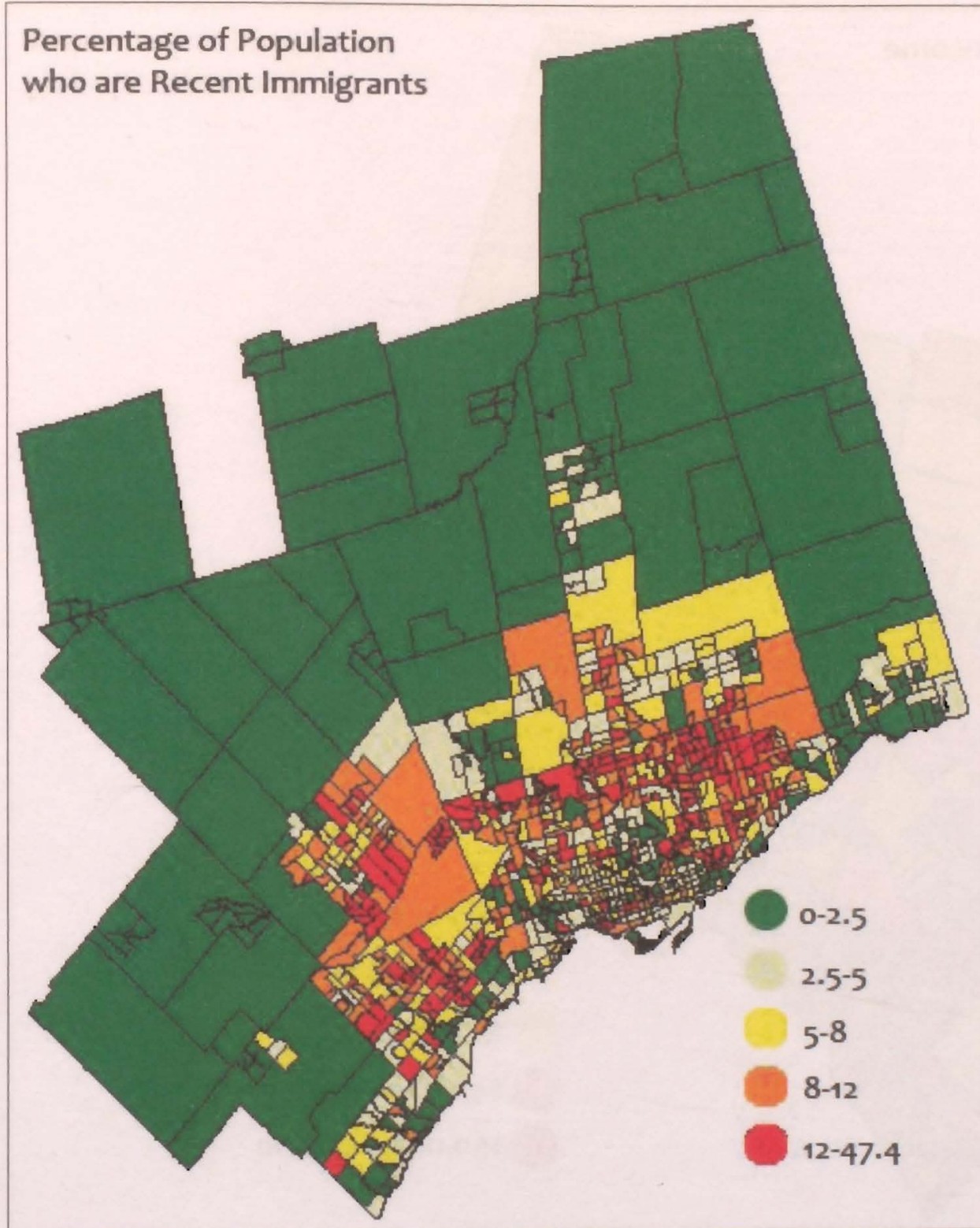




\section{Map 4}

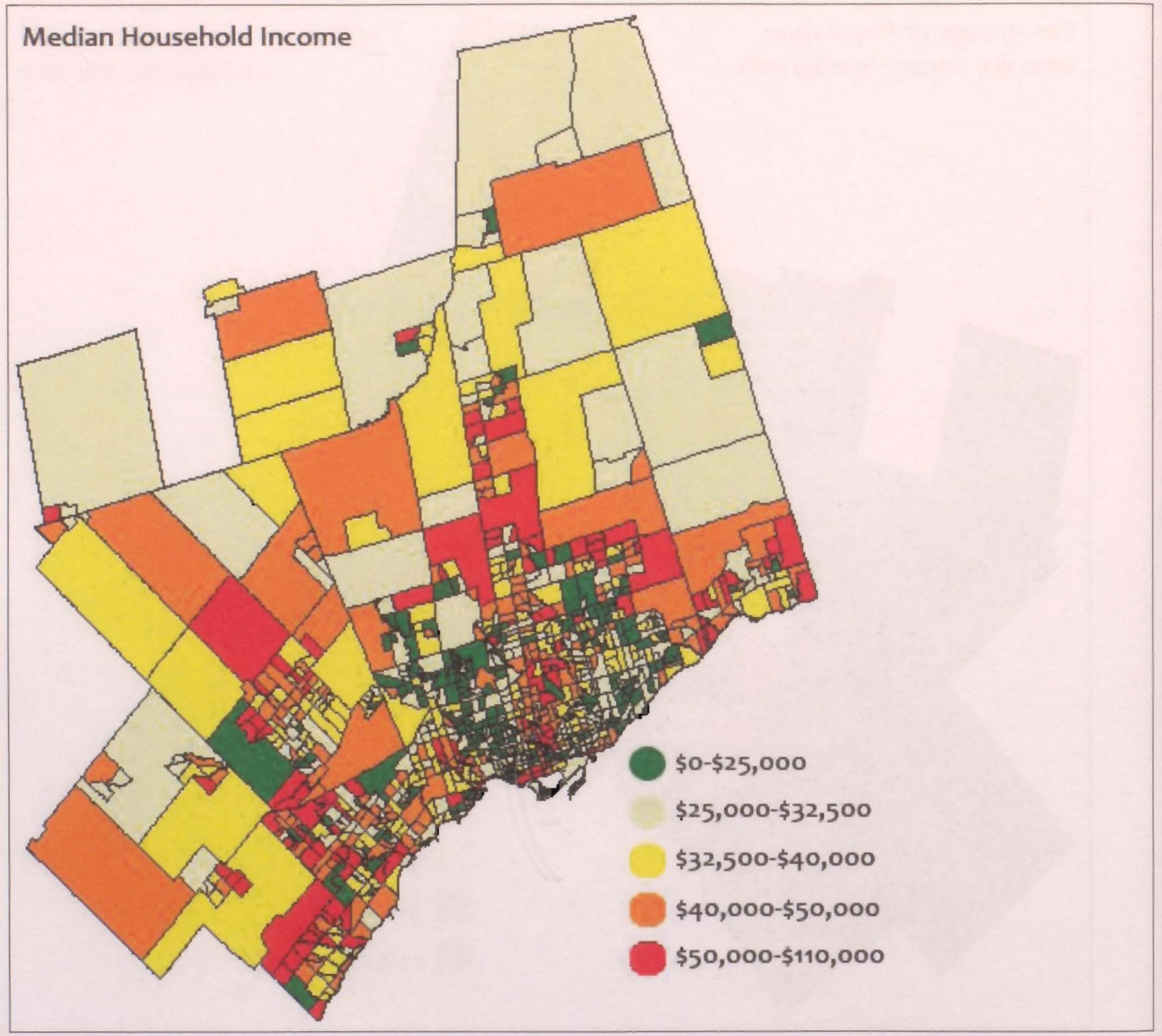


Map 5

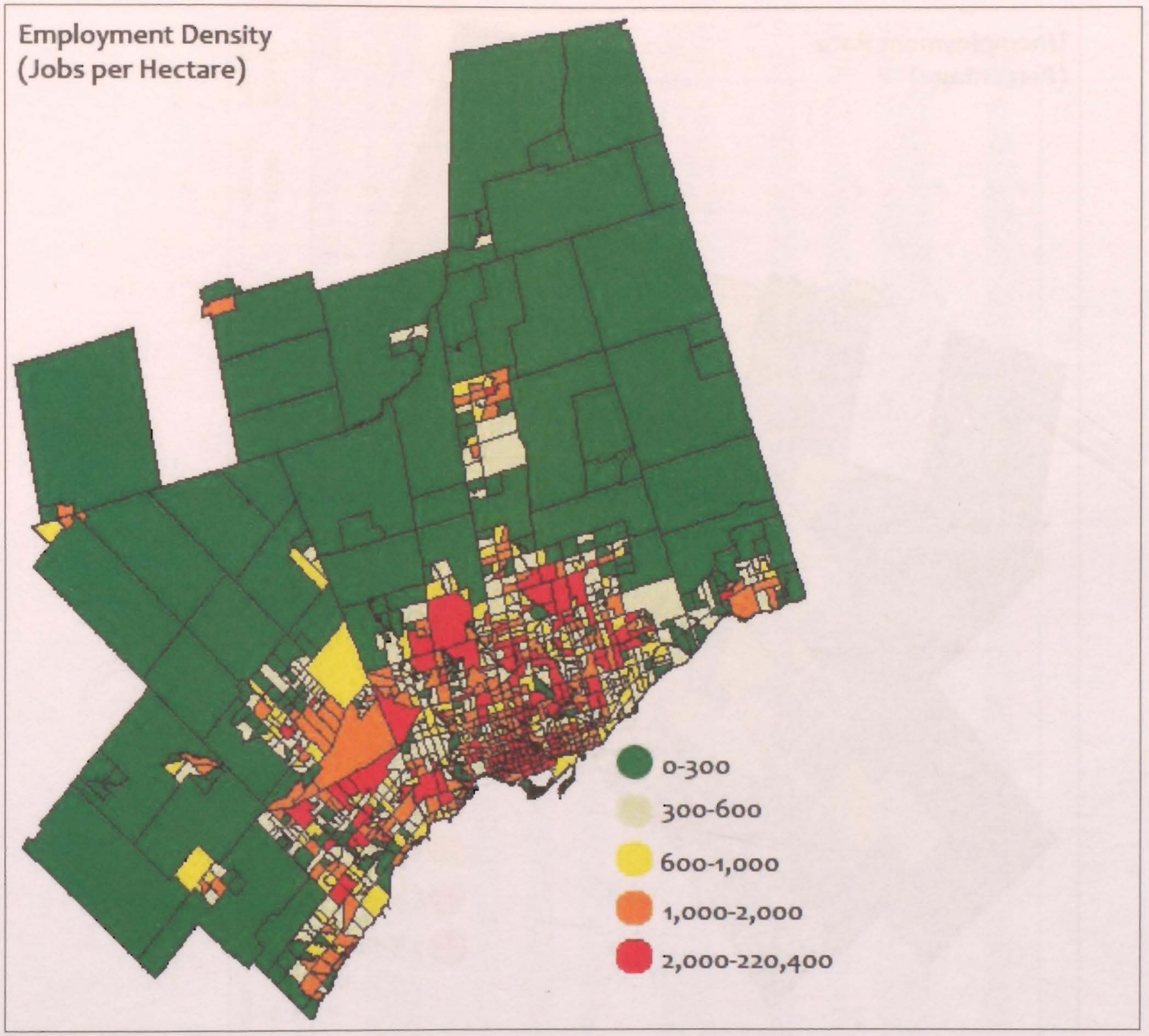


Map 6

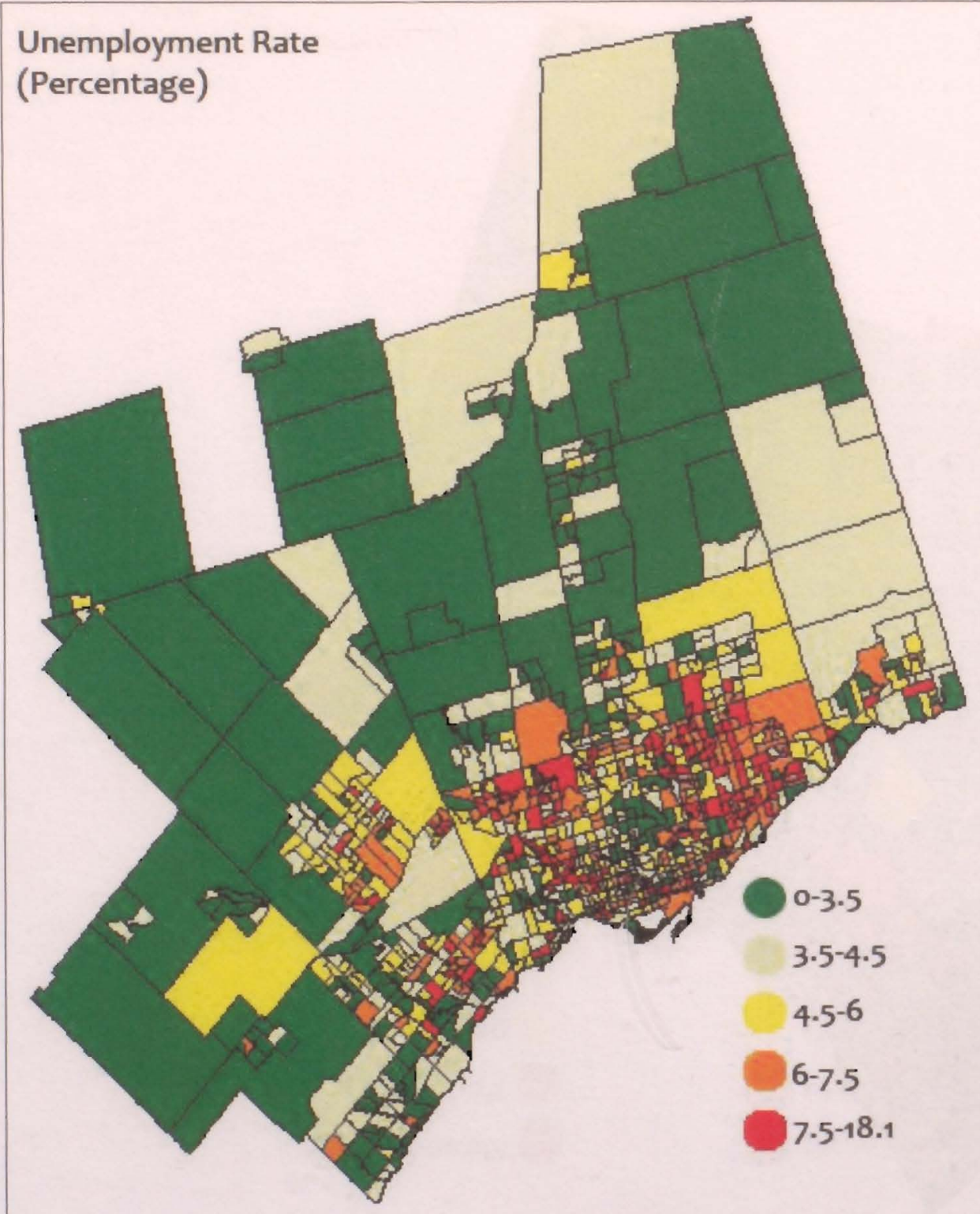




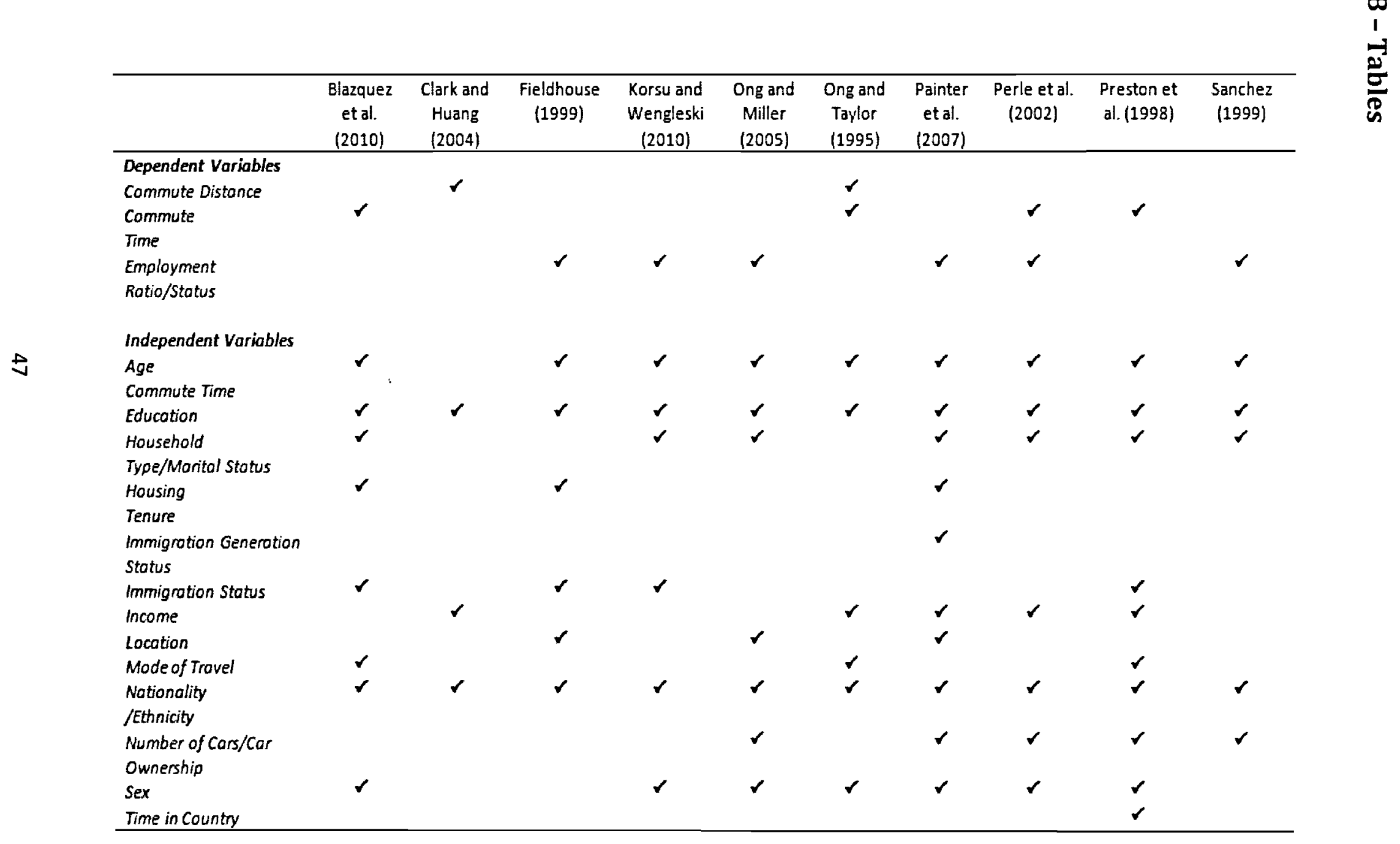


Table 2

\begin{tabular}{|c|c|c|}
\hline Variable & Description & Values \\
\hline \multicolumn{3}{|c|}{ Dependent Variable } \\
\hline \multirow[t]{5}{*}{ distrng } & Commuting Distance to Work & $1=0-5 \mathrm{~km}$ \\
\hline & & $2=5-10 \mathrm{~km}$ \\
\hline & & $3=10-15 \mathrm{~km}$ \\
\hline & & $4=15-25 \mathrm{~km}$ \\
\hline & & $5=25 \mathrm{~km}+$ \\
\hline \multicolumn{3}{|c|}{ Independent Variables } \\
\hline \multirow[t]{6}{*}{ timecan } & Time in Canada & $1=0-5$ years \\
\hline & & $2=5-10$ years \\
\hline & & $3=10-15$ years \\
\hline & & $4=15-20$ years \\
\hline & & $5=20+$ years \\
\hline & & $6=$ Canadian Born \\
\hline \multirow[t]{7}{*}{ hhsize } & Household Size & $1=$ One person \\
\hline & & $2=$ Two persons \\
\hline & & $3=$ Three Persons \\
\hline & & $4=$ Four Persons \\
\hline & & $5=$ Five Persons \\
\hline & & $6=$ Six Persons \\
\hline & & $7=$ Seven or more persons \\
\hline \multirow[t]{7}{*}{ hidegree } & $\begin{array}{l}\text { Highest Certificate, Degree or } \\
\text { Diploma }\end{array}$ & $1=$ None \\
\hline & & $2=$ High school or equivalency \\
\hline & & $3=$ Trades or apprenticeship \\
\hline & & certificate \\
\hline & & $4=$ College certificate or diploma \\
\hline & & $5=$ University undergraduate \\
\hline & & $6=$ Post-baccalaureate degree \\
\hline \multirow[t]{5}{*}{ hhincrng } & Household Income Groups & $1=\$ 0-\$ 49,999$ \\
\hline & & $2=\$ 50,000-\$ 74,999$ \\
\hline & & $3=\$ 75,000-\$ 99,999$ \\
\hline & & $4=\$ 100,000-\$ 149,999$ \\
\hline & & $5=\$ 150,000+$ \\
\hline \multirow[t]{2}{*}{ tenur } & Tenure & $\begin{array}{l}1=\text { Rented (for cash, other) or Band } \\
\text { housing }\end{array}$ \\
\hline & & $\begin{array}{l}2=\text { Owned (with or without } \\
\text { mortgage) }\end{array}$ \\
\hline \multirow[t]{2}{*}{ sex } & Gender & $1=$ Female \\
\hline & & $2=$ Male \\
\hline \multirow[t]{4}{*}{ agegrps } & Age Groups & $1=15-24$ \\
\hline & & $2=25-39$ \\
\hline & & $3=40-54$ \\
\hline & & $4=55-64$ \\
\hline
\end{tabular}




\section{References}

1. Arnott, R. (1998). Economic Theory and the Spatial Mismatch. Urban Studies, 35(7) 1171-1185.

2. Bauder, H. (2000). Reflections on the Spatial Mismatch Debate. Journal of Planning Education and Research, 19, 316-321.

3. Blázquez, M., Llano, C., \& Moral, J. (2010). Commuting Times: Is There Any Penalty for Immigrants? Urban Studies, 47(8) 1663-1686.

4. Blumenberg, E., \& Manville, M. (2004). Beyond the Spatial Mismatch: Recipients and Transportation Policy. Journal of Planning Literature, 19 (2) 182-205.

5. Cervero, R., Sandoval, O., \& Landis, J. (2002). Transportation as a stimulus of welfareto-work-Private versus public mobility. Journal of Planning Education and Research. 22 (1) $50-63$.

6. Fieldhouse, E.A. (1999). Ethnic Minority Unemployment and Spatial Mismatch: The Case of London. Urban Studies, 36(9) 1569-1596.

7. Gobillon, L., Selod, H., \& Zenou, Y. (2007). The Mechanisms of Spatial Mismatch. Urban Studies, 44 (12) 2401-2427.

8. Hanushek, E. A. (2008). John Forest Kain (1935-2003). The New Palgrave Dictionary of Economics. Houndmills, England: Palgrave Macmillan.

9. Kain, J. F. (1968). Housing Segregation, Negro Employment, and Metropolitan Decentralization. Quarterly Journal of Economics, 82(2) 175-197.

10. Korsu, E. \& Wenglenski, S. (2010). Job Accessibility, Residential Segregation and Risk of Long-term Unemployment in the Paris Region. Urban Studies, 47(11) 2279-2324.

11. Kweon, Y., \& Lee, J. (2010) Potential risk of using General Estimates System: Bicycle safety. Accident Analysis and Prevention, 42, 1712-1717.

12. Loveless, S. (1999). Access to jobs: Intersection of transportation, social and economic development policies-Challenge for transportation planning in the 21 st century. In Refocusing transportation planning for the 21st century: Proceedings of two conferences. Washington, DC: Transportation Research Board.

13. Mieszkowski, P., \& Mills, E. (1993) The causes of metropolitan suburbanization. Journal of Economic Perspectives, 7, 135-147.

14. Murakami, E., \& Young, J. (1997). Daily travel by persons with low income. Paper presented at the NPTS symposium in Bethesda, Maryland, October 29-31. Washington, 
DC: Federal Highway Administration, U.S. Department of Transportation. http://npts.ornl.gov/npts/1995/Doc/LowInc.pdf.

15. Ong, P. M. \& Miller, D. (2005). Spatial and Transportation Mismatch in Los Angeles. Journal of Planning Education and Research, 25 43-56.

16. Ong, P. M. \& Taylor, B. D. (1995). Spatial Mismatch or Automobile Mismatch? An Examination of Race, Residence and Commuting in US Metropolitan Areas. Urban Studies, 32 (9) 1453-1473.

17. Orfeuil, J. (2004). Transports, pauvretés, exclusions: pouvoir bouger pour s'en sortir. Paris: Editions de l'Aube.

18. Painter, G., Liu, C.Y., \& Zhuang, D. (2007). Immigrants and the Spatial Mismatch Hypothesis: Employment Outcomes among Immigrant Youth in Los. Urban Studies, 44(13) 2627-2649.

19. Perle, E.D., Bauder, H.,\& Beckett, N. (2002) Accessibility Measures in Spatial Mismatch Models. The Professional Geographer, 54 (1) $106-110$.

20. Preston, V., \& McLafferry, S. (1999). Spatial mismatch research in the 1990s: Progress and potential. Papers in Regional Science, 78, 387-402.

21. Preston, V., McLafferty, S., and Liu, X.F. (1998). Geographical Barriers to Employment for American-born and Immigrant Workers. Urban Studies, 35(3) 529-545.

22. Sanchez, T. W. (1999). The connection between public transit and employment: The cases of Portland and Atlanta. Journal of the American Planning Association, 65 (3) 284296.

23. Sayer, A. (1985). The difference that space makes. In Social Relations and Spatial Structures, eds. Derek Gregory and John Urry, 49-66. Basingstroke, U.K.: Macmillian.

24. Simpson, W. (1992). Urban structure and the labour market. Worker mobility, commuting, and underemployment in cities. Oxford: Oxford University Press.

25. Statistics Canada. (2008) Census of Canada, 2006: individual public use microdata file. Retrieved December 12, 2010 from http://sda.chass.utoronto.ca.ezproxy.lib.ryerson.ca/cgi-bin/sdacensus/hsda?harcsda + cc06i

26. Statistics Canada. (2008) CHASS Canadian Census Analyzer. Retrieved December 12, 2010 from http://dcl.chass.utoronto.ca.ezproxy.lib.ryerson.ca/census/2006/index.html/

27. Statistics Canada. 2007. Toronto, Ontario (Code535) (table). 2006 Community Profiles. 2006 Census. Statistics Canada Catalogue no. 92-591-XWE. Ottawa.

Released March 13, 2007. http://www12.statcan.ca/census-recensement/2006/dp- 
$\mathrm{pd} /$ prof/92-591/index.cfm?Lang=E

(accessed March 4, 2011).

28. Statistics Canada. (2010) 2006 Census Public Use Microdata File (PUMF) Individuals File Documentation and User guide. Statistics Canada Catalogue no. 95M0028XVB. Ottawa.

29. Wachs, M., \& Taylor, B. (1998). Can transportation strategies help meet the welfare challenge? Journal of the American Planning Association, 64 (1) 15-29.

30. Williams, R. (2006). Generalized ordered logit/partial proportional odds models for ordinal dependent variables. The Stata Journal, 6 (1) 58-82.

31. Zavodny, M. (1999) Determinants of recent immigrants locational choices, International Migration Review, 33(4) 1014-1030. 